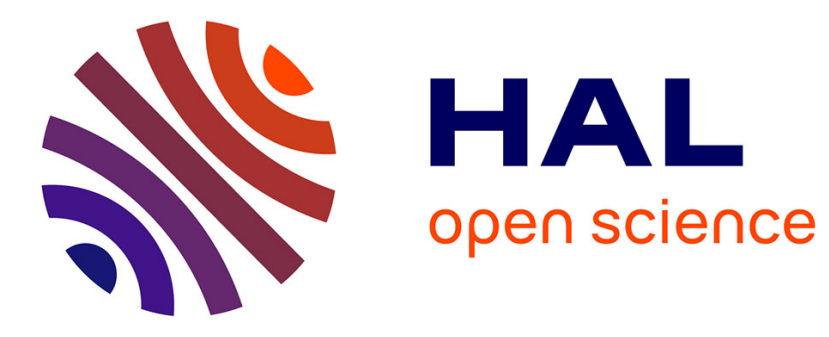

\title{
Maize and sunflower biomass estimation in southwest France using high spatial and temporal resolution remote sensing data
}

Martin Claverie, Valérie Demarez, Benoît Duchemin, Olivier Hagolle, Danielle Ducrot, Claire Marais-Sicre, Jean-François Dejoux, Mireille Huc, P. Keravec, Pierre Béziat, et al.

\section{To cite this version:}

Martin Claverie, Valérie Demarez, Benoît Duchemin, Olivier Hagolle, Danielle Ducrot, et al.. Maize and sunflower biomass estimation in southwest France using high spatial and temporal resolution remote sensing data. Remote Sensing of Environment, 2012, rse-08294, pp.1-14. 10.1016/j.rse.2012.04.005 . ird-00718813

\section{HAL Id: ird-00718813 https://hal.ird.fr/ird-00718813}

Submitted on 12 Dec 2012

HAL is a multi-disciplinary open access archive for the deposit and dissemination of scientific research documents, whether they are published or not. The documents may come from teaching and research institutions in France or abroad, or from public or private research centers.
L'archive ouverte pluridisciplinaire HAL, est destinée au dépôt et à la diffusion de documents scientifiques de niveau recherche, publiés ou non, émanant des établissements d'enseignement et de recherche français ou étrangers, des laboratoires publics ou privés. 


\section{$1 \quad$ Title}

2 Maize and sunflower biomass estimation in southwest France using high spatial and temporal

3 resolution remote sensing data

\section{$4 \quad$ Authors}

5 Claverie M. ${ }^{a}$, Duchemin B. ${ }^{a}$, Hagolle O. ${ }^{a}$, Ducrot D. ${ }^{a}$, Marais-Sicre C. ${ }^{a}$, Dejoux J.F. ${ }^{a}$, Huc M. ${ }^{a}$,

6 Keravec P. ${ }^{a}$, Béziat P. ${ }^{a}$, Fieuzal R. ${ }^{a}$, Ceschia E. ${ }^{a}$ and Dedieu G. ${ }^{a}$, Demarez V. ${ }^{a}$.

$7{ }^{a}$ CESBIO, Unité mixte CNES-CNRS-IRD-UPS, 18, avenue Edouard Belin, 31401 Toulouse Cedex 4,

8 France.

\section{$9 \quad$ Corresponding author}

10 Martin Claverie

11 Centre d'Etudes Spatiales de la BIOsphère

12 Address: CESBIO, 18 Avenue Edouard Belin, 31401 Toulouse Cedex 4, FRANCE

13 Telephone: +33561558543

14 Fax: +33561558500

15 E-mail: martin.claverie@gmail.com

16 
18 The recent availability of high spatial and temporal resolution (HSTR) remote sensing data 19 (Formosat-2, and future missions of Venus and Sentinel-2) offers new opportunities for crop 20 monitoring. In this context, we investigated the perspective offered by coupling a simple 21 algorithm for yield estimate (SAFY) with the Formosat-2 data to estimate crop production over

22 large areas. With a limited number of input parameters, the SAFY model enables the simulation

23 of time series of green area index (GAl) and dry aboveground biomass (DAM). From 2006 to 24 2009, 95 Formosat-2 images (8 meters, 1 day revisit) were acquired for a $24 \times 24 \mathrm{~km}^{2}$ area 25 southwest of Toulouse, France. This study focused on two summer crops: irrigated maize (Zea 26 mays) and sunflower (Helianthus annuus). Green area index (GAI) time series were deduced 27 from Formosat-2 NDVI time series and were used to calibrate six major parameters of the SAFY 28 model. Four of those parameters (partition-to-leaf and senescence function parameters) were 29 calibrated per crop type based on the very dense 2006 Formosat- 2 data set. The retrieved 30 values of these parameters were consistent with the in situ observations and a literature 31 review. Two of the major parameters of the SAFY model (emergence day and effective light-use 32 efficiency) were calibrated per field relative to crop management practices. The estimated 33 effective light-use efficiency values highlighted the distinction between the C4 (maize) and C3 34 (sunflower) plants, and were linked to the reduction of the photosynthesis rate due to water 35 stress. The model was able to reproduce a large set of GAI temporal shapes, which were related 36 to various phenological behaviours and to crop type. The biomass was well estimated (relative 
37 error of $28 \%$ ), especially considering that biomass measurements were not used for the 38 calibration. The grain yields were also simulated using harvest index coefficients and were

39 compared with grain yield statistics from the French Agricultural Statistics for the department of 40 Haute-Garonne. The inter-annual variation in the simulated grain yields of sunflower was 41 consistent with the reported variation. For maize, significant discrepancies were observed with 42 the reported statistics.

43 


\section{1. Introduction}

45 Soil carbon sequestration has been identified by the Intergovernmental Panel on Climate

46 Change as one of the options for the mitigation of greenhouse gases (Hutchinson et al. 2004).

47 Agricultural lands cover approximately $35 \%$ of the land surfaces and through photosynthesis

48 and biomass production, agriculture can act as carbon sinks (Ceschia et al. 2010, Kutsch et al.

49 2010). However, many factors impact photosynthesis, including crop type, crop management

50 practices, soil properties and climate. Thus, crop production is highly variable in both space and

51 time. This variability should be quantified to improve the management of agricultural lands and

52 to refine regional carbon balance estimates.

53 Land surfaces have been studied for many years using remote sensing reflectances and 54 vegetation indices (Baret and Guyot 1991, Asrar et al. 1994, Moulin et al. 1998, Bastiaanssen et

55 al. 2000, Basso et al. 2001, Pinter et al. 2003, Faivre et al. 2004, Scotford and Miller 2005,

56 Duchemin et al. 2008b). Crops fields of South-West of France are often of small size and they

57 experience high temporal dynamics due to plant growth and management practices (soil tillage,

58 sowing, irrigation and harvest). Remote sensing satellites providing high frequency observations

59 at a high spatial resolution are thus well designed to monitor cropping systems. Until recently,

60 high spatial and temporal resolutions have not been attainable because of technological

61 limitations. Currently, the Formosat-2 Taiwanese satellite has the unique capability of taking

62 daily images at $8 \mathrm{~m}$ spatial resolution with a constant viewing angle (Chern et al. 2006). The high

63 temporal resolution of the monodirectional Formosat-2 data allows the acquisition of very 
64 accurate surface reflectances and vegetation indices time series (Hagolle et al. 2008, Hagolle et 65 al. 2010).

66 Previously, only a small number of agro-meteorological studies have been performed using both

67 high spatial and temporal resolution images with constant viewing angles such as Formosat-2

68 data. Duchemin et al. (2008b) have presented a preliminary evidence of the usefulness of such

69 data for land use mapping and agricultural water management for wheat crops in Morocco.

70 Numerous studies (Courault et al. 2008, Bsaibes et al. 2009, Hadria et al. 2010, Fieuzal et al.

71 2011) have shown its utility for capturing the spatiotemporal variability of two key biophysical

72 variables: albedo and green leaf area index. Hadria et al. (2009) have demonstrated the

73 convenience of this type of data for the detection of agricultural operations such as ploughing

74 or irrigation at the beginning of the cropping season. In this study, we analysed the potential for

75 the use of high spatial and temporal resolution images to provide regular estimates of crop

76 production over large areas. We used Formosat-2 data in combination with a simple algorithm

77 for yield estimate (SAFY, Duchemin et al. 2008a).

78 Crop models were originally designed to simulate crop growth on agricultural fields where soil,

79 climate and agricultural practices were well known and spatially homogeneous. They have been

80 used in a wide range of agro-environmental issues. However, the application of crop models

81 over large areas is still challenging because the soil properties, the climatic variables and the

82 agricultural practices are highly variable in space and time (Boote et al. 1996, Moulin et al. 1998, 
83 Faivre et al. 2004, de Wit et al. 2005). In confronting this challenge, we have distinguished three

84 categories of crop models:

85 i) Complex models that simulate a large set of agro-environmental variables through the description of numerous coupled phenological and physiological processes, such as photosynthesis, respiration, evapotranspiration and nitrogen uptake (e.g., AFRCWHEAT2, CERES, Sirius, SUCROS2, STICS, SWHEAT, see Jamieson et al. 1998 and Brisson et al. 2003 for reviews). These models require a large number of parameters and input data. This information may be available during scientific experiments, or it may be available from some farmers at a local scale, but it is generally not available over large areas.

ii) In contrast, very simple models calculate biomass as an empirical sum of vegetation indices derived from remote sensing observations (Tucker and Sellers 1986, Dong et al. 2003, Wessels et al. 2006). These models are all based on the light-use efficiency (LUE) theory (Monteith 1977). These models are uncomplicated to parameterise over large areas using time series of remote sensing data with low spatial resolution data acquired at 10-day or monthly intervals. They provide estimates of net primary production for natural ecosystems such as forests (e.g., Dong et al. 2003) or grasslands (e.g., Tucker et al. 1983, Prince 1991, Wylie et al. 1991, Loseen et al. 1995). However, these models appear less suited for crop monitoring because they do not accurately account for crop type and management (Faivre et al. 2004). 
iii) The third category of crop models gathers the descriptions of the main biophysical processes (biomass accumulation, leaf partition, leaf senescence,...) and empirical parameterisations. These models combine the LUE theory with a simulation of the successive plant phenological phases. This semi-empirical approach, in which the number of formalisms and parameters is limited, enables studies over larger areas. Maas (1993) has demonstrated the value of such a model for simulating time series of leaf area index and dry aboveground biomass for maize and wheat crops. Lobell et al. (2003) and Liu et al. (2010), who worked on the combination of such semi-empirical models and remote sensing data, have underlined the need for high temporal and spatial resolution satellite data to improve model predictions.

112 The SAFY model (Duchemin et al. 2008a) belongs to this third category of semi-empirical

113 models. It was specifically designed for large-scale studies because it describes the main

114 biophysical processes using climatic data. Previous studies have shown that the SAFY model, 115 once calibrated with green leaf area index time series, resulted in accurate estimates of dry 116 aboveground biomass for irrigated wheat cultivated in semi-arid regions (Duchemin et al. 117 2008b, Hadria et al. 2009, Fieuzal et al. 2011).

118 The objective of this study was to evaluate the coupling between high spatial and temporal 119 resolutions remote sensing data with a simple crop model to estimate crop production at 120 regional scale. An example is shown using Formosat-2 images combined with the SAFY model 121 applied to sunflower (Helianthus annuus) and maize (Zea mays) in southwest France. The 
122 experiment was performed during four successive agricultural seasons (2006-2009) with a focus

123 on maize and sunflower crops, which are the two dominant summer crops cultivated in the

124 southwest of France. Time series of Formosat-2 observations were used to calibrate parameters

125 of the SAFY model over a region covering approximately $600 \mathrm{~km}^{2}$. Evaluation of the model used

126 an in situ data set collected from 2006 to 2009 and regional grain yield statistics.

\section{2. Material and methods}

\subsection{Study area}

129 The study area is a $24 \times 24 \mathrm{~km}^{2}$ area located near Toulouse, in southwest France $\left(1^{\circ} 10^{\prime} \mathrm{E}\right.$, $13043^{\circ} 27^{\prime} \mathrm{N}$, Fig. 1). The climate is temperate continental with hot (daily mean temperature 131 approximately $22.5^{\circ} \mathrm{C}$ ) and dry (38 mm/month of rainfall) summers. Arable lands cover up to $13260 \%$ of the study area, of which $40 \%$ is cultivated during summer, predominantly with irrigated 133 maize (grain and silage) and sunflower crops. The southeastern and the western parts of the

134 study area are hilly landscapes with small fields (approximately $10 \mathrm{ha}$ ); the centre of the study 135 area, near the Garonne River, is nearly flat with larger fields (approximately 25 ha).

136 In the study area, maize fields are sown from mid-April to beginning of June, and last until

137 September-October. Most of maize fields are irrigated during hottest month (July and August).

138 Sunflower fields are sown from end of March to end of June and are mainly non-irrigated. 


\subsection{Field data}

140 The study was performed during from 2006 to 2009 on maize and sunflower crops. Four types

141 of in situ data were measured: the dry aboveground biomass (DAM), the green area index (GAI)

142 and the fraction of absorbed photosynthetically active radiation (FAPAR). The DAM and the SLA

143 were estimated with a destructive method. The GAI and the FAPAR were estimated from

144 hemispherical photographs.

145 The main characteristics of the field measurements are shown in Fig. 1 and Table 1 . Two

146 protocols were used to collect the data:

(i) Transect sampling protocol: the measurements of DAM were performed from 2006 to 2008 along two transects crossing the field. This protocol was applied in two fields belonging to the CarboEurope-IP Regional experiment (Dolman et al. 2006). These two fields are hereafter referred to as "Lamothe" and "Auradé". They belong to an experimental farm managed by the Purpan Engineering School and to a farmers association (http://www.agriculteurs-aurade.fr/). Thirty plants were harvested 6 to 9 times per growing season (Table 1). For each plant, leaf biomasses were measured independently and leaf areas were measured using a planimeter (Licor 3100 Lincoln Inc., 155 Nebraska) in order to derive the specific leaf area (SLA).

(ii) Elementary sampling unit (ESU) protocol: the measurements of DAM, GAI and FAPAR were performed within a $20 \mathrm{~m}$ sided square area. Eleven fields located near the 
hereafter referred to as the ESU fields. The locations of the ESUs were recorded with a GPS. GAI and FAPAR were measured in 2008 using digital hemispherical photographs (DHPs). Each ESU was sampled with 13 DHPs applying the VALERI spatial sampling protocol (http://w3.avignon.inra.fr/valeri). The in situ data were collected 7 to 10 times during the growing season yielding $23 \mathrm{GAI}$ and FAPAR estimations for maize and 19 for sunflower (Table 1). The DAM was estimated from 10 plants collected near the ESUs in 2008 and 2009, leading to 14 DAM estimations for maize and 11 for sunflower. In 2009, only one biomass measurement was performed per ESU during the growing season.

167 The concept of green area index (GAI, Baret et al. 2010) corresponds to the photosynthetically 168 active plant area without organ distinctions. It is related to FAPAR and can be derived from 169 DHPs. In our study, the DHPs were taken with a Nikon CoolPix 8400 camera equipped with a FC-

170 E8 fisheye lens. The camera was put at the top of a pole to keep the viewing direction (looking

171 downward) and the canopy-to-sensor distance constant $(\sim 1.5 \mathrm{~m})$ throughout the growing 172 season. This protocol allowed the reduction of errors in the directional gap fraction estimates 173 and thus in the FAPAR and GAl estimates (Demarez et al. 2008). The DHP were processed using

174 CAN-EYE V5 (http://www4.paca.inra.fr/can-eye), which provides estimates of the daily FAPAR 175 and of the "effective" and "true" GAI (Demarez et al. 2008, Baret et al. 2010). In this study, we 176 used the effective GAI (GAl eff,CAN-EYE$_{\text {, which }}$ is highly correlated with remote sensing 177 observations and the daily FAPAR (FAPAR daily,CAN-EYE ). 
178 In addition to these measurements, several farmers provided grain yield estimates for maize (4

179 estimates) and sunflower (37 estimates) for 12 fields located near Lamothe and for 16 fields

180 located near Auradé (blue disks in Fig. 1).

\subsection{Meteorological data}

182 Meteorological data were generated by the mesoscale atmospheric analysis system SAFRAN,

183 which is operational at Météo-France (Durand et al. 1993). Among other variables, SAFRAN

184 simulates air temperature at $2 \mathrm{~m}$ above the ground (Ta), incoming global radiation ( $\mathrm{Rg}$ ) and

185 precipitation $(\mathrm{P})$ based on a combination of measurements (weather stations) and modelling.

186 The data are available every 6 hours over a grid with an $8 \mathrm{~km}$ spatial resolution (plus symbols in

187 Fig. 1).

188 The SAFRAN meteorological variable data were processed to compute daily mean Ta and 189 cumulated daily $\mathrm{Rg}$ and $\mathrm{P}$ for each Fomosat-2 pixel (8 meters) of the study area. The spatial 190 oversampling was performed using a bilinear spatial interpolation.

191 The evaluation performed by Quintana-Segui et al. (2008) all over the France have shown that

$192 \operatorname{Rg}($ RRMSE $=60 \%)$ and Ta (RRMSE $=13 \%)$ are accurately estimated by SAFRAN, while the

193 accuracy of $P$ was found lower (RRMSE $=100 \%)$, especially in mountainous areas.

194 The analysis of the meteorological variables over the Formosat-2 footprint revealed differences 195 between the years. The driest and hottest years were 2006 and 2009; the cumulated daily 196 precipitation for the summer growing season, from DoY (day of year) 125 to 250 , was $147 \mathrm{~mm}$ 
197 in 2006 and $152 \mathrm{~mm}$ in 2009, whereas it reached $248 \mathrm{~mm}$ in 2008 and $273 \mathrm{~mm}$ in 2007. The

198 cumulated air temperature during the same period was approximately $2570{ }^{\circ} \mathrm{C}$ in 2006 and

1992009 and approximately $2370^{\circ} \mathrm{C}$ in 2007 and 2008.

200

\subsection{Formosat-2 data}

201 Formosat-2 is a high spatial (8 meters) and temporal (daily revisit time) resolution satellite with

202 four spectral bands (488, 555, 650 and $830 \mathrm{~nm}$ ) and a $24 \mathrm{~km}$ field of view (Chern et al. 2006).

203 Formosat-2 takes images at a constant viewing angle. Ninety-Five images were taken of our

204 study area from 2006 to 2009 (Fig. 2). In 2006, the images were scheduled at a high priority

205 level with a nominal time step of 3 days. The 2006 data set contained 51 images, including 27

206 images that were almost totally cloud-free. After 2006, only images with a cloud cover less than

207 20\% were purchased. Thus, 14 images were available in 2007, 11 images in 2008 and 19 in 2009.

208 In 2008, no cloud-free images were available from February 11 to June 19.

209 All of the Formosat-2 images were pre-processed for geometric, radiometric and atmospheric

210 corrections and the filtering of clouds and shadows (Hagolle et al. 2008, Hagolle et al. 2010).

211 This processing resulted in surface reflectances images and associated cloud-masks. The

212 absolute location accuracy was 0.4 pixels, i.e., $3.2 \mathrm{~m}$ (Baillarin et al. 2008), which is quite

213 satisfactory with respect to both the field and ESU sizes.

$214 \quad 2.5 . \quad$ Land cover 
215 Maize and sunflower were identified using classification and segmentation methods applied to

216 Formosat-2 surface reflectances images. This processing was performed each year using all

217 images acquired from January to December. The classification method was performed using a

218 fuzzy contextual algorithm of the Iterative Conditional Mode type based on a Markovian model

219 (Idbraim et al. 2009). The segmentation algorithm was based on a watershed method (Fjortoft

220 et al. 1999) and leaded to homogenous units (called HU hereafter), corresponding to

221 homogenous radiometric zones. The parameters used for the segmentation were chosen such

222 that the agricultural fields were split in the case of high intra-field variability. As a result, an

223 agricultural field corresponded to one or several HU (see Fig. 3). Only HU larger than $640 \mathrm{~m}^{2}$ (10

224 Formosat-2 pixels) and covered by a minimum of $80 \%$ of either maize or sunflower pixels were

225 considered in this study.

226 Each year, this processing provided 40 land use classes, from which maize (grain and silage) and

227 sunflower were extracted. The analysis of the mapped HU showed that:

228 (i) Sunflower and maize crops covered approximately $21 \%$ of the study area.

229 (ii) Maize was primarily cultivated in the centre of the Formosat-2 images, near the

230 Garonne River. It covered approximately 7700 ha in 2006, 6500 ha in 2007, 7400 ha in

2312008 and 6600 ha in 2009. The maize crops were segmented into HU of 2 ha on average.

232 Approximately $95 \%$ of these $\mathrm{HU}$ were identified as grain maize, the remaining $5 \%$ being

233 silage maize. 
(ii) Sunflower was cultivated throughout the study area and was dominant over the hill landscapes at the eastern and western part of the study area. Sunflower crops covered approximately 6300 ha in 2006, 5100 ha in 2007, 7200 ha in 2008 and 7200 ha in 2009. Sunflower was segmented into smaller HU than maize of approximately 0.7 ha on average. This was expected as sunflower crops were not irrigated and were often cultivated on hills. Thus, these crops exhibited a higher intra-field variability due to the variation in soil properties and water availability.

\subsection{Time series of Green Area Index (GAI)}

242 Many studies have demonstrated the link between spectral vegetation indices (e.g., NDVI, SAVI

243 and $\mathrm{EVI}$ ) derived from remote sensing observations and the green leaf area index (e.g., Myneni

244 1994, Weiss et al. 2002, Colombo et al. 2003, Walthall 2004, Duchemin et al. 2006). In our study,

245 the green area index $\left(\mathrm{GAl}_{\mathrm{eff}, \mathrm{F} 2}\right)$ was estimated from the Formosat-2 images using the NDVI and

246 the following exponential relationship (Eq. 1):

$$
G A I_{\mathrm{eff}, \mathrm{F} 2}=k_{1} \times e^{k_{2} \times N D V I}-k_{3}
$$

248 The coefficients of Eq. 1 were estimated using the minimisation of the root mean square error

249 (RMSE) between $\mathrm{GAl}_{\text {eff,CAN-EYE }}$ estimated from the DHPs from the ESUs and $\mathrm{GAl}_{\text {eff,F2 }}$ estimated 250 from Eq. 1. The $\mathrm{GAl}_{\text {eff,CAN-EYE }}$ measurements taken more than 4 days after or before the

251 Formosat-2 acquisitions were eliminated from the data set. The NDVI-GAl eff,CAN-EYE $_{\text {Scatterplot is }}$ 252 presented in Fig. 4. A single relationship (the black line in Fig. 4) was used for both crops 
253 (coefficients $\mathrm{k}_{1}=0.35, \mathrm{k}_{2}=2.86, \mathrm{k}_{3}=0.24$ in Eq. 1). The RMSE between $\mathrm{GAl}_{\text {eff,CAN-EYE }}$ and GAl $\mathrm{eff}, \mathrm{F} 2_{2}$ was

254 equal to $0.38 \mathrm{~m}^{2} \cdot \mathrm{m}^{-2}$ and the relative RMSE (RRMSE) was equal to $20 \%$. The formulation of the

255 equation differed from more commonly used logarithmic formulation. Nevertheless, the current

256 formulation fitted correctly with the in situ measurements of effective GAl. With the current set

257 of coefficients, the GAl estimate could not exceed $5.9 \mathrm{~m}^{2} \cdot \mathrm{m}^{-2}$, which was sufficient as it

258 corresponded to effective GAl.

259 This relationship was then applied to all Formosat-2 pixels. This processing resulted in a time 260 series of effective Formosat-2 GAl (called hereinafter $\mathrm{GAl}_{\mathrm{F} 2}$ ), which were spatially averaged over

261 the HU labelled as maize (silage or grain) and sunflower. During the calculation, all of the data

262 with cloudy or shadowed pixels were excluded.

263

\subsection{Calibration of the SAFY model}

264 The simple algorithm for yield estimates (SAFY) is a daily time step model that simulates time

265 series of leaf area index and dry aboveground biomass from the air temperature and the global

266 incoming radiation. An overview of the model is provided in the Appendix 1; a full description is

267 available in Duchemin et al. (2008a).

268 The model was parameterised for each HU labelled as maize (silage or grain) or sunflower using

269 meteorological data derived from SAFRAN. The thirteen parameters of the SAFY model are

270 listed in Table 2. Initial values were put based on a literature review and field measurements for 
271 eight parameter and the six major parameters, identified by Duchemin et al. (2008a), were

272 calibrated using only time series of green area index derived from Formosat-2 images $\left(\mathrm{GAl}_{\mathrm{F} 2}\right)$.

273

274

275

276 in Duchemin et al. (2008a), the initial dry aboveground biomass was set arbitrarily to

277 correspond with a GAl of $0.1 \mathrm{~m}^{2} \cdot \mathrm{m}^{-2}$.

278 The three critical temperature values ( $T_{\min }, T_{\max }, T_{\text {opt }}$, Eq. 3 in the Appendix 1 ) and the degree of

279 the polynomial function $(\beta)$ that defines the stress temperature function for each crop were 280 obtained from Drouet and Pages (2003) and from the STICS website

281 (http://www.avignon.inra.fr/agroclim stics/).

282 The light-extinction coefficient ( $k_{\text {ext }}$ ) was computed by inverting Beer's law (Eq. 5 in the

283 Appendix 1) using the fraction of absorbed photosynthetically active radiation (FAPAR daily,CAN-EYE)

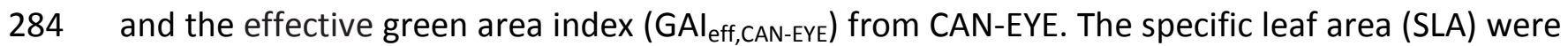

285 estimated from measurements of leaf biomass and leaf area done at Lamothe in 2006 (maize)

286 and at Auradé in 2007 (sunflower). Only measurements before the maximum GAl were

287 considerate.

288 2.7.2. Calibration of parameters based on remote sensing data 
289 The remaining parameters $\left(\mathrm{Pl}_{\mathrm{a}}, \mathrm{Pl}_{\mathrm{b}}, \mathrm{Stt}, \mathrm{Rs}, \mathrm{D}_{0}\right.$ and $\left.\mathrm{ELUE}\right)$ were all retrieved using only $\mathrm{GAl}_{\mathrm{F} 2}$ time 290 series derived from Formosat-2 images. To limit compensation during the optimisation 291 procedure (see Duchemin et al. 2008a), we classified the parameters in two groups: crop292 specific and field-specific parameters. Two corresponding phases were used for the calibration.

293 The methodology of the calibration is described in the Fig. 5. The four crop specific parameters

$294\left(\mathrm{Pl}_{\mathrm{a}}, \mathrm{Pl}_{\mathrm{b}}, \mathrm{Stt}, \mathrm{Rs}\right)$, which constrain the shape of the $\mathrm{GAl}_{\mathrm{F} 2}$ time course, were calibrated, on phase

2951 , separately for sunflower, grain maize and silage maize. The two field specific parameters $\left(D_{0}\right.$ 296 and ELUE) were calibrated, on phase 2, for each HU.

297 Prior to the calibration procedure, a delimitation of the growing period was needed (Fig. 6). The 298 day of maximum GAl F2 (DoY 218 in Fig. 6) was first identified. The algorithm then seeks 299 backward from this day to determine the starting day of the growing period (DoY 156 in Fig. 6), 300 which was defined as the day that exhibited a $\mathrm{GAl}_{\mathrm{F} 2}$ value less than a user-defined threshold.

301 This threshold was set as the minimum $\mathrm{GAl}_{\mathrm{F} 2}$ value, encountered in the backward seek, plus 0.1.

302 The end of the growing season (DoY 288 in Fig. 6) was identified in a similar way, seeking 303 forward before the day of maximum $\mathrm{GAI}_{\mathrm{F} 2}$. The $\mathrm{GAI}_{\mathrm{F} 2}$ values that did not belong to the identified 304 growing period were excluded (plus symbols in Fig. 6).

305 The calibration of SAFY was then performed by minimising the Root Mean Square Error (RMSE) 306 between the "cleaned" GAl ${ }_{\mathrm{F} 2}$ time series and the GAl simulated by SAFY. The minimisation 307 procedure was based on an adapted version of the simplex method (Lagarias et al. 1998), which 308 was run 50 times with a random determination of initial values to avoid stops in local minima. 
309 Intervals of acceptable values were defined for each parameter (Table 2). These intervals were

310 constant for all of the parameters except the date of emergence, for which the interval was

311 established independently for each HU to plus or minus 20 days around the start of the growing

312 period.

313 The crop-specific parameters were estimated, on phase 1 of the calibration (see Fig. 5), using

314 the $\mathrm{GAl}_{\mathrm{F} 2}$ time series of the $6032 \mathrm{HU}$ deduced from the 2006 Formosat-2 data set. This data set

315 was preferred as it contained a high number of images regularly distributed during the whole

316 growing season. Depending on the HU, 18 to 28 cloud-free images were available from May to

317 September. $\mathrm{HU}$ with maximum $\mathrm{GAI}_{\mathrm{F} 2}$ less than $1 \mathrm{~m}^{2} \cdot \mathrm{m}^{-2}$ or that lead to RMSE superior to 0.38

$318 \mathrm{~m}^{2} \cdot \mathrm{m}^{-2}$ were not kept in our analysis as they were considered to be incorrectly classified.

319 However, an important set (95\%) of crop-specific parameters ( $\left.\mathrm{Pl}_{\mathrm{a}}, \mathrm{Pl}_{\mathrm{b}}, \mathrm{Stt}, \mathrm{Rs}\right)$ was available for

320 each crop: 1980 for grain maize, 97 for silage maize and 3644 for sunflower. A median value was

321 then computed for each crop and used on phase 2 of the calibration (see Fig. 5) to constrain the

322 estimation the field-specific parameters ( $D_{0}$ and ELUE). These latter parameters were estimated

323 per year and per spatial pattern: HU for Formosat-2 footprint estimates, and transect, ESU and

324 field for local estimates. The minimisation procedure of phase 2 was based on a regular simplex

325 method because there is no compensation between these two parameters (Duchemin et al. 326 2008a).

\section{3. Results and discussion}


328 In this section, results of the calibration and the validation are discussed. The two parameters, 329 estimated from in situ measurements are first discussed. The parameters, estimated from the $330 \mathrm{GAl}_{\mathrm{F} 2}$ are then described: crop-specific $\left(\mathrm{Pl}_{\mathrm{a}}, \mathrm{Pl}_{\mathrm{b}}\right.$, Stt and $\mathrm{Rs}$ ) and field-specific (ELUE and $\left.\mathrm{D}_{0}\right)$.

331 Finally, the validations at local and regional scales are described in the two last sections.

\section{1. $\quad$ Light-extinction coefficient and Specific Leaf Area}

333 Fig. 7 displays the relationship between the fraction of absorbed photosynthetically active

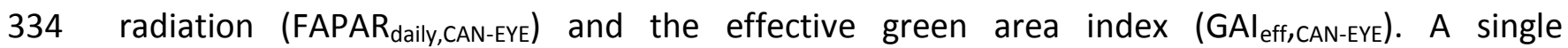
335 relationship was used for both crops. The best agreement was obtained using a light-extinction 336 coefficient $\left(K_{\text {ext }}\right)$ of 0.63 (see Eq. 5 in the Appendix 1). The RMSE between FAPAR derived from

337 this relationship and FAPAR daily,CAN-EYE was 0.033 .

338 The relationship between the leaf area and leaf mass is displayed in Fig. 8. These two variables 339 were linearly related. SLA values corresponding to the slopes of the relationships (Fig. 8) were 340 used in the SAFY simulations: $0.012 \mathrm{~m}^{2} \cdot \mathrm{g}^{-1}$ for sunflower and $0.024 \mathrm{~m}^{2} \cdot \mathrm{g}^{-1}$ for maize.

\subsection{Crop-specific parameters}

342 Fig. 9 shows the box and whiskers plots of the distributions of the crop specific parameters $\left(\mathrm{PI}_{\mathrm{a}}\right.$,

$343 \mathrm{Pl}_{b}$, Stt and Rs) for maize (grain: $\mathrm{M}$ and silage: $\mathrm{SM}$ ) and sunflower (SF) based on phase 1 of the 344 calibration applied on the $5721 \mathrm{HU}$ of the 2006 Formosat-2 data set. Their median values are 345 reported in Table 2 and the distributions appeared very scattered. As previously suggested by 
346 Duchemin et al. (2008a), part of this scattering can be attributed to parameter compensations

347 occurring during the minimisation procedure. The parameters appeared more scattered for

348 sunflower than for maize likely because sunflower crops, which are not irrigated, are much

349 more sensitive to the spatial distribution of rainfall and to soil water content than is maize. They

350 thus experienced larger variations in the $\mathrm{GAI}_{\mathrm{F} 2}$ time series.

351 "Typical" maize (grain and silage) and sunflower $\mathrm{GAl}_{F 2}$ time series computed from three $\mathrm{HU}$ of

352 the 2006 Formosat-2 data set are plotted on Fig. 10. The analysis of Fig. 9, Fig. 10 and Table 2

353 revealed that significant information could be derived from the distributions of the crop specific

354 parameters:

355 (i) The dry aboveground biomass allocated to the leaf at plant emergence (1-PI $\left.{ }_{a}\right)$ was $65 \%$

356 for grain maize, $66 \%$ for silage maize and $84 \%$ for sunflower (Fig. 9). These values were consistent with the ratios of the leaf mass to the dry aboveground biomass derived from in situ measurements at the beginning of the agricultural season, which were $75 \%$ for maize (Lamothe in 2006) and 83\% for sunflower (Auradé in 2007).

(ii) No significant difference was observed between the grain and silage parameters, except the rate of senescence (Rs in Table 2), which was approximately 15 times higher for silage maize. This very high rate of senescence for silage maize corresponded with the sudden drop of $\mathrm{GAl}_{\mathrm{F} 2}$ due to harvesting as illustrated in Fig. 10. Silage maize is used to feed animals and thus it is harvested earlier than grain maize, when grain humidity reaches $80 \%$. 
(iii) Senescence began earlier for sunflower than for maize. The threshold of cumulated temperature to initiate senescence was estimated to be $70 \%$ lower for sunflower than for maize (Stt in Table 2). This difference is well illustrated in the $\mathrm{GAl}_{\mathrm{F} 2}$ time series (Fig. 10) and was previously shown by Andrade (1995).

\section{3. $\quad$ Field specific parameters}

371 The cumulated distribution of the effective light-use efficiency (ELUE) and the emergence dates

$372\left(D_{0}\right)$ estimated for the sunflower and maize crops of the Formosat- 2 footprint are presented in

373 Fig. 11 ( $a$ to d). Numbers of HU used to compute the cumulated distribution are shown in the

374 Fig. 11 ( $a$ and $b)$. The cumulated distributions of the maximum $G A I\left(G A I_{\max }\right)$, the rainfall and the

375 temperature stress factor are also plotted (Fig. 11 e to j). The rainfall was cumulated from 30

376 days before emergence to senescence. The temperature stress factor corresponds to the

377 average of the $F_{\mathrm{T}}$ function (Eq. 3 in the Appendix 1) from emergence to senescence.

378 The median value of the ELUE averaged over the four years was 3.3 g. $\mathrm{MJ}^{-1}$ for maize (Fig. 11a)

379 and 2.0 g.MJ ${ }^{-1}$ for sunflower (Fig. 11b). The SAFY model thus appeared adequate to reproduce 380 the basic difference in photosynthetic rate between maize (C4 plant) and sunflower (C3 plant).

381 The ELUE values for sunflower increased from 2006 to 2008 in relation with the increasing 382 values of cumulated rainfall (Fig. 11h). This is consistent as this parameter is expected to include 383 water stress effect. A similar positive correlation was observed between the median values of 384 cumulated rainfall and $\mathrm{GAI}_{\max }$ (Fig. 11f). In contrast, the inter-annual variation in maize ELUE was 385 not related to the rainfall. This is consistent as maize is irrigated to avoid water stress. The 21 
386 analysis of the distribution of $\mathrm{GAI}_{\max }$ (Fig. 11e) permitted the explanation of the inter-annual

387 maize ELUE variations. In 2006 and 2009, the $\mathrm{GAI}_{\max }$ values were similar despite differences in

388 temperature stress factors, which were highest in 2009 (Fig. 11i). Thus, the calibration

389 procedure induced highest ELUE values in 2009 (Fig. 11a) to compensate for the negative effect

390 of low temperatures on GAl. The same trend was observed in 2007 and 2008; the highest values

391 of temperature stress factor and ELUE were found in 2007. These results revealed that the

$392 \mathrm{GAl}_{\max }$ is a good indicator of water or temperature stresses and that the model and the

393 calibration procedure proposed here were able to reproduce such effects.

394 The emergence dates $\left(D_{0}\right)$ were also significantly different between maize (Fig. 11c) and 395 sunflower (Fig. 11d). For maize, the median value was stable over the years and was

396 approximately 164 (June, 13). The plant emergence always occurred within a limited time 397 period; each year, $90 \%$ of all of the $D_{0}$ values were within $+/-15$ days of the annual median 398 value. For sunflower, $D_{0}$ was more variable and $90 \%$ of the $D_{0}$ values were within $+/-45$ days of 399 the annual median value. This was consistent with difference in irrigation between the crops; 400 sunflower is not irrigated and thus is more sensitive to the spatial variability of rainfall events 401 and soil properties, which may induce strong differences between fields. 
404 A quantitative evaluation of the model was performed by comparing the dry aboveground 405 biomass (DAM) simulated by SAFY with those estimated from field measurements. The spatial 406 pattern used for the validation corresponded to the footprint of in situ data: transect, ESU and 407 field. The model was calibrated using the $\mathrm{GAl}_{\mathrm{F} 2}$ time series averaged over the pixels that 408 encompassed transects (sunflower at Auradé in 2007 and maize at Lamothe in 2006 and 2008), 409 over a $3 \times 3$ pixel window centred on the ESUs (2008 and 2009) or over the pixels that 410 encompassed fields where grain yields were collected. The $\mathrm{GAl}_{\mathrm{F} 2}$ and DAM time series from 4112006 to 2008 resulting from this processing are displayed in Fig. 12.

412 The analysis of the simulated GAl time series confirmed that the SAFY model was able, after 413 calibration, to reproduce the large range of the observed $\mathrm{GAl}_{\mathrm{F} 2}$ shapes. The maximum $\mathrm{GAl}_{\mathrm{F} 2}$ 414 values of maize were quite low $\left(<3.5 \mathrm{~m}^{2} \cdot \mathrm{m}^{-2}\right)$, which is expected as effective values are proven 415 to underestimate destructive values. This underestimation could reach $30 \%$ for the maize and $41616 \%$ for the sunflower as shown by Demarez et al. (2008). The continuous GAl increase during 417 leaf growth appeared to be accurately reproduced for all of the crops. The difference observed 418 in the time duration of maximal GAl between the sunflower and the maize is also well 419 reproduced. Finally, the GAl decrease during the senescence period was correctly simulated for 420 all crops except for the sunflower crop in 2008 (case 6, Fig. 12); the observed sudden decrease 421 was not simulated by the SAFY model. Hemispherical photographs (Fig. 13) taken in 2008 on July 42217 and 24 (referred to as A and B in Fig. 12) revealed that the NDVI and GAl decrease 423 corresponded with flowering. 
424 The temporal dynamics of DAM were correctly reproduced in most of cases. Most of the 425 simulated values ranged within the averages plus or minus the standard deviation of the field 426 measurements. However, some discrepancies were noted:

427 (i) In 2008, the maximum DAM produced by the grain maize (case 3, Fig. 12) was underestimated by approximately $29 \%$ in relative terms. The deviation may be explained by the lack of consideration of an increase of the light use efficiency (LUE) allocated to decreases.

(ii) In contrast with maize, the maximum DAM produced by sunflower (cases 4 and 6 in Fig. 12) were overestimated. The maximum dry aboveground biomass was unfortunately not measured for case 5. Recent work by Lecoeur et al. (2011) performed with similar sunflower varieties showed that ELUE decreases from the flowering phase, probably in favour of lipids production. The slight decrease in DAM observed before senescence in the measured biomass was due to measurement errors.

439 The global comparison between simulated and measured DAM from 2006 to 2009 is presented 440 on Fig. 14 and Table 3. There is a good agreement between simulations and field 441 measurements, with a high correlation $\left(r^{2}=0.92, p\right.$-value $\left.<0.001\right)$, almost no bias $\left(-0.02 \mathrm{~kg} \cdot \mathrm{m}^{-2}\right)$ 442 and an error (RMSE) of $0.21 \mathrm{~kg} \cdot \mathrm{m}^{-2}$. The correlation is higher for silage maize $\left(r^{2}=0.96 ;\right.$ RRMSE = $44311 \%)$ than for grain maize $\left(r^{2}=0.86\right.$; RRMSE $\left.=26 \%\right)$ and sunflower $\left(r^{2}=0.78 ;\right.$ RRMSE $\left.=39 \%\right)$. The 
444 global accuracy of simulations (RRMSE $=28 \%$ on Fig. 14) was satisfactory considering that the

445 most sensitive parameters of the model were only calibrated with remote sensing observations.

446 This accuracy was comparable to that of studies using more complex models with a large in situ

447 data set. They found accuracy of $14 \%$ and $32 \%$ for maize using SWATRER-SUCROS and CERES

448 (Xevi et al. 1996), 16\% using STICS (Brisson et al. 2002) and 23\% using EPIC (Cabelguenne et al.

449 1999). An accuracy of 21\% was found for sunflower using EPIC (Cabelguenne et al. 1999).

450 The SAFY model was also run for fields for which farmers provided grain yields. The in situ grain

451 yields were compared with the maximum simulated DAM (Fig. 15). The data for sunflower were

452 highly scattered. This was partially due to the overestimations of the SAFY biomass and partially

453 due to uncertainties in the in situ grain yields. For maize, too few measurements were available

454 to exhibit a trend. Despite these limitations, a mean harvest index (HI) was computed for each

455 crop as the ratio of in situ grain yields to the maximum DAM. This index was 0.48 for grain maize

456 and 0.25 for sunflower. The $\mathrm{HI}$ calculated for maize appeared consistent with those from

457 previous experimental or modelling studies; Cabelguenne et. al (1999) reported a value of 0.5.

458 Due to the SAFY biomass overestimation, the $\mathrm{HI}$ calculated for sunflower was very low

459 compared with the in situ values given by Casadebaig (2008), which varied between 0.35 and $460 \quad 0.45$ 
463 The distributions of the maximum aerial dry biomass (DAM ${ }_{\max }$ ) estimated over the whole 464 Formosat-2 footprint are presented in Fig. 16. For sunflower, the maximum DAM values (Fig. 465 16b) were reached during the wettest year (2008, Fig. 11h). In 2007, despite the strong rainfall, 466 the $\mathrm{DAM}_{\max }$ values were not as high as in 2008. In 2007, we noticed that the period of 467 emergence was quite long, up to 200 days (Fig. 11d). This was due to heavy rains during the 468 spring, which limited plant emergence, particularly in clay soils, and thus limited the crop 469 production. For maize, the highest maximum DAM values were reached during the hottest years 470 (Fig. 11i).

471 The DAM $M_{\max }$ values averaged over four years were equal to approximately $19.5 \mathrm{t}^{-h^{-1}}$ for maize 472 and 9.6 t.ha $^{-1}$ for sunflower. The grain yields calculated from these averaged DAM $_{\max }$ values 473 using the harvest index previously estimated (0.48 for maize and 0.25 for sunflower) were 10.1

474 t.ha ${ }^{-1}$ for maize and 2.4 t.ha ${ }^{-1}$ for sunflower and were in agreement with the values given by the 475 French Agricultural Statistics for the whole department of Haute-Garonne, which were 10.2 t.ha $^{-}$ $476{ }^{1}$ for maize and 2.3 t.ha $^{-1}$ for sunflower (Fig. 17, Agreste 2011). The accuracy of the sunflower 477 grain yield estimation was due to compensation between the overestimated biomass and the 478 underestimated harvest index. Nevertheless, the inter-annual variations of the estimated 479 sunflower grain yields were highly correlated with the reported statistics $(r=0.97, p$-value $<0.03$, 480 Fig. 17). The lowest simulated grain yields were found in 2006 which was the driest year (Fig. 481 11h) like in the reported statistics; the highest simulated grain yields were found in 2008 which 482 was the wettest year like in the reported statistics. 
483 In contrast with sunflower, the inter-annual variation in the maize grain yields did not match the 484 reported grain yield statistics ( $r=-0.81$, Fig. 17). The lowest simulated grain yields were found in 4852008 , which was the year with the highest reported grain yields. The highest simulated grain 486 yields were estimated for 2009, which had the lowest reported grain yields. As discussed 487 previously, there was a clear effect of temperature on maize leaf and biomass production. We 488 may notice that the reported statistics are given for the entire department of Haute-Garonne, 489 which covers an area much larger than the Formosat-2 footprint. In contrast with the sunflower 490 crops, which are mainly located in the northern part of the department, the maize crops are 491 distributed throughout the department, which exhibits a strong spatial gradient in air

492 temperatures. The mean air temperatures were cumulated during the growing period using the 493 SAFRAN data. They varied from $2419{ }^{\circ} \mathrm{C}$ (in 2007) to $2646{ }^{\circ} \mathrm{C}$ (in 2006) in the northern part of the 494 department and from $2001{ }^{\circ} \mathrm{C}$ (in 2007) to $2202{ }^{\circ} \mathrm{C}$ (in 2006) in the southern part of the 495 department. The differences observed in cumulative temperature between the northern and 496 the southern part of the department could reach $400{ }^{\circ} \mathrm{C}$. The Formosat-2 footprint was located 497 in the northern part of the department with a cumulative air temperature varying from $2353{ }^{\circ} \mathrm{C}$ 498 (in 2007) to $2600{ }^{\circ} \mathrm{C}$ (in 2006). Thus, the SAFY simulations performed over the maize crops were 499 considered to not be representative of the entire department of Haute-Garonne and thus 500 unfortunately not comparable with the reported statistics.

\section{4. Conclusion}


502 In this study, we evaluated the combined use of high spatial and temporal resolutions remote 503 sensing data and a simple crop model to estimate maize and sunflower crops production. A

504 semi-empirical crop model (SAFY, Duchemin et al. 2008a) was calibrated with high temporal and 505 spatial resolution Formosat-2 data available from 4 years (2006 to 2009). The results revealed 506 that the high frequency of the 2006 Formosat- 2 data set (27 cloud free images throughout the 507 year) permitted the estimation of phenological parameters $\left(\mathrm{Pl}_{a}, \mathrm{pl}_{\mathrm{b}}\right.$, Stt and Rs), which were 508 proven to be crop dependant. Once calibrated, these parameters were used to calibrate 509 effective light-use efficiency (ELUE) and emergence dates $\left(D_{0}\right)$, and to simulate biomass from 5102006 to 2009. From 2007 to 2009, fewer images were available, but the method remained 511 robust because it relied on the pre-calibration of the phenological parameters using the 2006 512 high temporal resolution data set. Analysis of the ELUE values showed that the SAFY model was

513 able to reproduce the basic difference in photosynthetic rate between maize (C4 plant) and 514 sunflower (C3 plant). The simulation of $D_{0}$ revealed higher variability of non-irrigated sunflower 515 than irrigated maize. The SAFY model was also able to reproduce the temporal variability of $516 \mathrm{GAl}_{\mathrm{F} 2}$ shape and dry aboveground biomass through the 4 studied years. The errors retrieved

517 from the comparison between destructive sampling and simulated biomass were consistent 518 (RMSE $=0.22 \mathrm{~kg} \cdot \mathrm{m}^{-2} ;$ RRMSE $=29 \%$ ) in comparison with the values given by authors who used 519 more complex models. However, this approach faced some limitations. First, the use of the

5202006 Formosat-2 data set to calibrate phenological parameters $\left(\mathrm{Pl}_{a}, \mathrm{pl}_{\mathrm{b}}\right.$, Stt and $\left.\mathrm{Rs}\right)$ is a potential

521 source of error. Indeed, the unusual hot at dry meteorological conditions of 2006 impacted the 522 value of calibrated parameters and, thus, all estimations of biomass. Secondly, in the SAFY 
523 model, the ELUE is constant over the phenological cycle, which could lead to errors in the dry

524 aboveground biomass estimations. For example, Lecoeur et al. (2011) showed that the ELUE of

525 sunflower decreased during the maturity phase. We consequently suggest a future adaptation

526 of the SAFY model by implementing variation with time for ELUE particularly after flowering.

527 The results also showed that the maximum $\mathrm{GAl}_{\mathrm{F} 2}$ value was a good indicator of the canopy

528 water and temperature stress. Thus the need of a temperature stress function like used into the

529 SAFY model should be questioned through further studies.

530 Finally, inter-annual variation in grain yields over the entire Formosat-2 data set of images (24 $\mathrm{x}$

$53124 \mathrm{~km}^{2}$ ) was estimated using maize and sunflower and compared with grain yield statistics given

532 by the French Agricultural Statistics for the entire department of Haute-Garonne $\left(6300 \mathrm{~km}^{2}\right)$.

533 The SAFY model was able to correctly reproduce the inter-annual variation in the grain yield of

534 sunflower $\left(r^{2}=0.89\right)$. In contrast, the inter-annual variation of maize grain yield was not

535 correctly reproduced because of the lack of spatial representativeness of our model simulations.

536 This study demonstrates the great potential for the use of high spatial and temporal resolution

537 remote sensing data for large-scale crop monitoring. Nevertheless, the high spatial resolution

538 was not fully exploited as simulations were carried out over homogenous unit. Future studies

539 could focus on analysing the intra-field variability by applying such approach at pixel level.

540 Future satellite missions such as Venus (Dedieu et al. 2006) and Sentinel-2, which will provide

541 high spatial and temporal resolution images with a 4/5 days revisiting period and with a high 
542 number of spectral bands (12/13 spectral bands), will offer new perspectives for such 543 applications. 


\section{$544 \quad$ Acknowledgements}

545 This work was made possible through the support of the European Commission (FEDER Interreg

546 IVa program, ref POCTEFA 08/34, Fluxpyr), the French Ministry in Charge of Research ("Réseau

547 Terre et Espace"), the Centre National de la Recherche Scientifique (CNRS), the Institut National

548 des Sciences de I'Univers (INSU), the Centre National d'Etudes Spatiales (CNES) and the Région

549 Midi-Pyrénées Council. We are very grateful to the farmers of Auradé and Lamothe and to

550 Michel Gay from E.I. Purpan for granting and facilitating our access to their fields. We also

551 express gratitude to Eric Martin from CNRM-GAME (Météo France) for providing the SAFRAN

552 meteorological data. We finally would like to thank Marie Weiss and Frédéric Baret from

553 EMMAH (INRA Avignon) for the support on CAN-EYE software. Special thanks to our technical

554 staff: Hervé Gibrin, Nicole Ferroni and Bernard Marciel. 


\section{$555 \quad$ References}

556 Agreste (2011). La statistique Agricole. Ministère de l'agriculture et de la pêche.

557 http://www.agreste.agriculture.gouv.fr, last access: May 2011.

558 Andrade, F.H. (1995). Analysis of growth and yield of maize, sunflower and soybean grown at

559 Balcarce, Argentina. Field Crops Research, 41, 1-12.

560 Asrar, G., Fuchs, M., Kanemasu, E.T., \& Hatfield, J.L. (1984). Estimating absorbed

561 photosynthetic radiation and leaf-area index from spectral reflectance in wheat. Agronomy

562 Journal, 76, 300-306.

563 Baillarin, S., Gigord, P., \& O., H. (2008). Atomatic Registration of optical images, a stake for

564 future missions: application to ortho-rectification, time series and mosaic products. 2008 Ieee

565 International Geoscience and Remote Sensing Symposium, Vols 1-8, 928-931.

566 Baret, F., \& Guyot, G. (1991). Potentials and limits of vegetation indexes for lai and apar 567 assessment. Remote Sensing of Environment, 35, 161-173.

568 Baret, F., Hagolle, O., Geiger, B., Bicheron, P., Miras, B., Huc, M., Berthelot, B., Nino, F.,

569 Weiss, M., Samain, O., Roujean, J.L., \& Leroy, M. (2007). LAI, fAPAR and fCover CYCLOPES

570 global products derived from VEGETATION - Part 1: Principles of the algorithm. Remote

571 Sensing of Environment, 110, 275-286.

572 Baret, F., de Solan, B., Lopez-Lozano, R., Ma, K., \& Weiss, M. (2010). GAI estimates of row

573 crops from downward looking digital photos taken perpendicular to rows at 57.5 degrees zenith 
574 angle: Theoretical considerations based on 3D architecture models and application to wheat 575 crops. Agricultural and Forest Meteorology, 150, 1393-1401.

576 Basso, B., Ritchie, J.T., Pierce, F.J., Braga, R.P., \& Jones, J.W. (2001). Spatial validation of crop 577 models for precision agriculture. Agricultural Systems, 68, 97-112.

578 Bastiaanssen, W.G.M., Molden, D.J., \& Makin, I.W. (2000). Remote sensing for irrigated 579 agriculture: examples from research and possible applications. Agricultural Water Management, $580 \quad 46,137-155$.

581 Boote, K.J., Jones, J.W., \& Pickering, N.B. (1996). Potential uses and limitations of crop models. 582 Agronomy Journal, 88, 704-716.

583 Brisson, N., Ruget, F., Gate, P., Lorgeau, J., Nicoullaud, B., Tayot, X., Plenet, D., Jeuffroy, 584 M.H., Bouthier, A., Ripoche, D., Mary, B., \& Justes, E. (2002). STICS: a generic model for 585 simulating crops and their water and nitrogen balances. II. Model validation for wheat and maize. 586 Agronomie, 22, 69-92.

587 Brisson, N., Gary, C., Justes, E., Roche, R., Mary, B., Ripoche, D., Zimmer, D., Sierra, J., 588 Bertuzzi, P., Burger, P., Bussiere, F., Cabidoche, Y.M., Cellier, P., Debaeke, P., Gaudillere, J.P., 589 Henault, C., Maraux, F., Seguin, B., \& Sinoquet, H. (2003). An overview of the crop model 590 STICS. European Journal of Agronomy, 18, 309-332.

591 Bsaibes, A., Courault, D., Baret, F., Weiss, M., Olioso, A., Jacob, F., Hagolle, O., Marloie, O., 592 Bertrand, N., Desfond, V., \& Kzemipour, F. (2009). Albedo and LAI estimates from 593 FORMOSAT-2 data for crop monitoring. Remote Sensing of Environment, 113, 716-729. 
594 Cabelguenne, M., Debaeke, P., \& Bouniols, A. (1999). EPICphase, a version of the EPIC model 595 simulating the effects of water and nitrogen stress on biomass and yield, taking account of 596 developmental stages: validation on maize, sunflower, sorghum, soybean and winter wheat. 597 Agricultural Systems, 60, 175-196.

598 Casadebaig, P. (2008). Analyse et modélisation des interactions génotype - environnement 599 conduite de culture : application au tournesol (Helianthus annuus). In, Agrosystèmes et 600 développement territorial (AGIR). Toulouse.

601 Ceschia, E., Beziat, P., Dejoux, J.F., Aubinet, M., Bernhofer, C., Bodson, B., Buchmann, N., 602 Carrara, A., Cellier, P., Di Tommasi, P., Elbers, J.A., Eugster, W., Gruenwald, T., Jacobs, C.M.J., 603 Jans, W.W.P., Jones, M., Kutsch, W., Lanigan, G., Magliulo, E., Marloie, O., Moors, E.J., 604 Moureaux, C., Olioso, A., Osborne, B., Sanz, M.J., Saunders, M., Smith, P., Soegaard, H., \& 605 Wattenbach, M. (2010). Management effects on net ecosystem carbon and GHG budgets at 606 European crop sites. Agriculture Ecosystems \& Environment, 139, 363-383.

607 Chern, J.S., Wu, A.M., \& Lin, S.F. (2006). Lesson learned from FORMOSAT-2 mission 608 operations. Acta Astronautica, 59, 344-350.

609 Colombo, R., Bellingeri, D., Fasolini, D., \& Marino, C.M. (2003). Retrieval of leaf area index in 610 different vegetation types using high resolution satellite data. Remote Sensing of Environment, 611 86, 120-131.

612 Courault, D., Bsaibes, A., Kpemlie, E., Hadria, R., Hagolle, O., Marloie, O., Hanocq, J.F., 613 Olioso, A., Bertrand, N., \& Desfonds, V. (2008). Assessing the potentialities of FORMOSAT-2 
614 data for water and crop monitoring at small regional scale in South-Eastern France. Sensors, 8, $615 \quad 3460-3481$.

616 Dedieu, G., Karnieli, A., Hagolle, O., Jeanjean, H., Cabot, F., Ferrier, P., \& al., e. (2006).

617 VEN $\mu \mathrm{S}$ : A joint Israel-French Earth Observation scientific mission with High spatial and 618 temporal resolution capabilities. In, Second Recent Advances in Quantitative Remote Sensing 619 symposium. Torrent.

620 Demarez, V., Duthoit, S., Baret, F., Weiss, M., \& Dedieu, G. (2008). Estimation of leaf area and 621 clumping indexes of crops with hemispherical photographs. Agricultural and Forest 622 Meteorology, 148, 644-655.

623 Dolman, A.J., Noilhan, J., Durand, P., Sarrat, C., Brut, A., Piguet, B., Butet, A., Jarosz, N., 624 Brunet, Y., Loustau, D., Lamaud, E., Tolk, L., Ronda, R., Miglietta, F., Gioli, B., Magliulo, V., 625 Esposito, M., Gerbig, C., Korner, S., Glademard, R., Ramonet, M., Ciais, P., Neininger, B., 626 Hutjes, R.W.A., Elbers, J.A., Macatangay, R., Schrems, O., Perez-Landa, G., Sanz, M.J., Scholz, 627 Y., Facon, G., Ceschia, E., \& Beziat, P. (2006). The CarboEurope regional experiment strategy. 628 Bulletin of the American Meteorological Society, 87, 1367-+.

629 Dong, J.R., Kaufmann, R.K., Myneni, R.B., Tucker, C.J., Kauppi, P.E., Liski, J., Buermann, W., 630 Alexeyev, V., \& Hughes, M.K. (2003). Remote sensing estimates of boreal and temperate forest 631 woody biomass: carbon pools, sources, and sinks. Remote Sensing of Environment, 84, 393-410

632 Drouet, J.L., \& Pages, L. (2003). GRAAL: a model of GRowth, Architecture and carbon 633 ALlocation during the vegetative phase of the whole maize plant - Model description and 634 parameterisation. Ecological Modelling, 165, 147-173. 
635 Duchemin, B., Hadria, R., Erraki, S., Boulet, G., Maisongrande, P., Chehbouni, A., Escadafal, R., 636 Ezzahar, J., Hoedjes, J.C.B., Kharrou, M.H., Khabba, S., Mougenot, B., Olioso, A., Rodriguez, 637 J.C., \& Simonneaux, V. (2006). Monitoring wheat phenology and irrigation in Central Morocco: 638 On the use of relationships between evapotranspiration, crops coefficients, leaf area index and 639 remotely-sensed vegetation indices. Agricultural Water Management, 79, 1-27.

640 Duchemin, B., Maisongrande, P., Boulet, G., \& Benhadj, I. (2008a). A simple algorithm for yield 641 estimates: Evaluation for semi-arid irrigated winter wheat monitored with green leaf area index. 642 Environmental Modelling \& Software, 23, 876-892.

643 Duchemin, B., Hagolle, O., Mougenot, B., Benhadj, I., Hadria, R., Simonneaux, V., Ezzahar, J., 644 Hoedjes, J., Khabba, S., Kharrou, M.H., Boulet, G., Dedieu, G., Er-Raki, S., Escadafal, R., 645 Olioso, A., \& Chehbouni, A.G. (2008b). Agrometerological study of semi-arid areas: an 646 experiment for analysing the potential of time series of FORMOSAT-2 images (Tensift647 Marrakech plain). International Journal of Remote Sensing, 29, 5291-5300.

648 Durand, Y., Brun, E., Mérindol, L., Guyomarc'h, G., Lesaffre, B., \& Martin, E. (1993). A 649 meteorological estimation of relevant parameters for snow models. In (pp. 65-71): Annals of 650 Glaciology.

651 Faivre, R., Leenhardt, D., Voltz, M., Benoît, M., Papy, F., Dedieu, G., \& Wallach, D. (2004). 652 Spatialising crop models. Agronomie, 24, 205-217.

653 Fieuzal, R., Duchemin, B., Jarlan, L., Zribi, M., Baup, F., Merlin, O., Dedieu, G., Garatuza654 Payan, J., Watt, C., \& Chehbouni, A. (2010). Combined use of optical and radar satellite data for 655 the monitoring of irrigation and soil moisture of wheat crops. (pp. 6207-6242). 
656 Fjortoft, R., Lopes, A., Bruniquel, J., \& Marthon, P. (1999). Optimal edge detection and edge 657 localization in complex SAR images with correlated speckle. Ieee Transactions on Geoscience 658 and Remote Sensing, 37, 2272-2281.

659 Flenet, F., Kiniry, J.R., Board, J.E., Westgate, M.E., \& Reicosky, D.C. (1996). Row spacing 660 effects on light extinction coefficients of corn, sorghum, soybean, and sunflower. Agronomy 661 Journal, 88, 185-190.

662 Hadria, R., Duchemin, B., Baup, F., Le Toan, T., Bouvet, A., Dedieu, G., \& Le Page, M. (2009). 663 Combined use of optical and radar satellite data for the detection of tillage and irrigation 664 operations: Case study in Central Morocco. Agricultural Water Management, 96, 1120-1127.

665 Hadria, R., Duchemin, B., Jarlan, L., Dedieu, G., Baup, F., Khabba, S., Olioso, A., \& Le Toan, T. 666 (2010). Potentiality of optical and radar satellite data at high spatio-temporal resolutions for the 667 monitoring of irrigated wheat crops in Morocco. International Journal of Applied Earth 668 Observation and Geoinformation, 12, S32-S37.

669 Hagolle, O., Dedieu, G., Mougenot, B., Debaecker, V., Duchemin, B., \& Meygret, A. (2008).

670 Correction of aerosol effects on multi-temporal images acquired with constant viewing angles:

671 Application to Formosat-2 images. Remote Sensing of Environment, 112, 1689-1701.

672 Hagolle, O., Huc, M., Pascual, D.V., \& Dedieu, G. (2010). A multi-temporal method for cloud 673 detection, applied to FORMOSAT-2, VEN $\mu$ S, LANDSAT and SENTINEL-2 images. Remote 674 Sensing of Environment, 114, 1747-1755. 
675 Hutchinson, J.J., Campbell, C.A., \& Desjardins, R.L. (2004). Some perspectives on carbon 676 sequestration in agriculture. In, International Workshop on Contribution of Agriculture to the 677 State of Climate (pp. 288-302). Ottawa, CANADA: Elsevier Science Bv.

678 Idbraim, S. (2009). Méthodes d'extraction de l'information spatiale et de classification en 679 imagerie de télédétection : Applications à la cartographie thématique de la région d'Agadir 680 (Maroc). In, Sciences de l'Univers, de l'Environnement et de l'Espace (p. 149). Toulouse: 681 Université Toulouse III - Paul Sabatier.

682 Jamieson, P.D., Porter, J.R., Goudriaan, J., Ritchie, J.T., van Keulen, H., \& Stol, W. (1998). A 683 comparison of the models AFRCWHEAT2, CERES-wheat, Sirius, SUCROS2 and SWHEAT 684 with measurements from wheat grown under drought. Field Crops Research, 55, 23-44.

685 Kutsch, W.L., Aubinet, M., Buchmann, N., Smith, P., Osborne, B., Eugster, W., Wattenbach, M., 686 Schrumpf, M., Schulze, E.D., Tomelleri, E., Ceschia, E., Bernhofer, C., Beziat, P., Carrara, A., 687 Di Tommasi, P., Gruenwald, T., Jones, M., Magliulo, V., Marloie, O., Moureaux, C., Olioso, A., 688 Sanz, M.J., Saunders, M., Sogaard, H., \& Ziegler, W. (2010). The net biome production of full 689 crop rotations in Europe. Agriculture Ecosystems \& Environment, 139, 336-345.

690 Lagarias, J.C., Reeds, J.A., Wright, M.H., \& Wright, P.E. (1998). Convergence properties of the 691 Nelder-Mead simplex method in low dimensions. Siam Journal on Optimization, 9, 112-147.

692 Lecoeur, J., Poire-Lassus, R., Christophe, A., Pallas, B., Casadebaig, P., Debaeke, P., Vear, F., \& 693 Guilioni, L. (2011). Quantifying physiological determinants of genetic variation for yield 694 potential in sunflower. SUNFLO: a model-based analysis. Functional Plant Biology, 38, 246695259. 
696 Lindquist, J.L., Arkebauer, T.J., Walters, D.T., Cassman, K.G., \& Dobermann, A. (2005). Maize

697 radiation use efficiency under optimal growth conditions. Agronomy Journal, 97, 72-78.

698 Liu, J.G., Pattey, E., Miller, J.R., McNairn, H., Smith, A., \& Hu, B.X. (2010). Estimating crop 699 stresses, aboveground dry biomass and yield of corn using multi-temporal optical data combined 700 with a radiation use efficiency model. Remote Sensing of Environment, 114, 1167-1177.

701 Lobell, D.B., Asner, G.P., Ortiz-Monasterio, J.I., \& Benning, T.L. (2003). Remote sensing of 702 regional crop production in the Yaqui Valley, Mexico: estimates and uncertainties. Agriculture 703 Ecosystems \& Environment, 94, 205-220.

704 Loseen, D., Mougin, E., Rambal, S., Gaston, A., \& Hiernaux, P. (1995). A regional sahelian 705 grassland model to be coupled with multispectral satellite data .2. toward the control of its 706 simulations by remotely-sensed indexes. Remote Sensing of Environment, 52, 194-206.

707 Maas, S.J. (1993). Parameterized model of gramineous crop growth .1. leaf-area and dry mass 708 simulation. Agronomy Journal, 85, 348-353.

709 Monteith, J.L. (1977). Climate and efficiency of crop production in britain. Philosophical 710 Transactions of the Royal Society of London Series B-Biological Sciences, 281, 277-294.

711 Moulin, S., Bondeau, A., \& Delecolle, R. (1998). Combining agricultural crop models and 712 satellite observations: from field to regional scales. International Journal of Remote Sensing, 19, 713 1021-1036.

714 Myneni, R.B., \& Williams, D.L. (1994). On the relationship between FAPAR and NDVI. Remote 715 Sensing of Environment, 49, 200-211. 
716 Pinter, P.J., Hatfield, J.L., Schepers, J.S., Barnes, E.M., Moran, M.S., Daughtry, C.S.T., \&

717 Upchurch, D.R. (2003). Remote sensing for crop management. Photogrammetric Engineering 718 and Remote Sensing, 69, 647-664.

719 Prince, S.D. (1991). A model of regional primary production for use with coarse resolution 720 satellite data. International Journal of Remote Sensing, 12, 1313-1330.

721 Quintana-Segui, P., Le Moigne P., Durand Y., Martin E., Habets F., Baillon M., Canellas C., 722 Franchisteguy L. \& Morel S. (2008). Analysis of near-surface atmospheric variables : Validation of

723 the safran analysis over France, Journal of Applied Meteorology and Climatology, 47 (1), 92-107.

724 Scotford, I.M., \& Miller, P.C.H. (2005). Applications of spectral reflectance techniques in

725 Northern European cereal production: A review. Biosystems Engineering, 90, 235-250.

726 Tucker, C.J., Vanpraet, C., Boerwinkel, E., \& Gaston, A. (1983). Satellite remote-sensing of total

727 dry-matter production in the senegalese sahel. Remote Sensing of Environment, 13, 461-474.

728 Tucker, C.J., \& Sellers, P.J. (1986). Satellite remote-sensing of primary production. International 729 Journal of Remote Sensing, 7, 1395-1416.

730 Varlet-Grancher, C., Bonhomme, R., Chartier, M., \& Artis, P. (1982). Efficience de la conversion 731 de l'énergie solaire par un couvert végétal. In (pp. 3-26): Acta Oecologia/Oecologia Plantarum

732 Walthall, C., Dulaney, W., Anderson, M., Norman, J., Fang, H.L., \& Liang, S.L. (2004). A 733 comparison of empirical and neural network approaches for estimating corn and soybean leaf 734 area index from Landsat ETM+ imagery. Remote Sensing of Environment, 92, 465-474. 
735 Weiss, M., Baret, F., Leroy, M., Hautecoeur, O., Bacour, C., Prevot, L., \& Bruguier, N. (2002).

736 Validation of neural net techniques to estimate canopy biophysical variables from remote sensing 737 data. Agronomie, 22, 547-553.

738 Wessels, K.J., Prince, S.D., Zambatis, N., Macfadyen, S., Frost, P.E., \& Van Zyl, D. (2006).

739 Relationship between herbaceous biomass and 1-km(2) Advanced Very High Resolution

740 Radiometer (AVHRR) NDVI in Kruger National Park, South Africa. International Journal of

741 Remote Sensing, 27, 951-973.

742 Wit de, A.J.W., Boogaard, H.L., \& van Diepen, C.A. (2005). Spatial resolution of precipitation 743 and radiation: The effect on regional crop yield forecasts. Agricultural and Forest Meteorology, $744 \quad 135,156-168$.

745 Wylie, B.K., Harrington, J.A., Prince, S.D., \& Denda, I. (1991). Satellite and ground-based 746 pasture production assessment in Niger - 1986-1988. International Journal of Remote Sensing, $747 \quad 12,1281-1300$.

748 Xevi, E., Gilley, J., \& Feyen, J. (1996). Comparative study of two crop yield simulation models. 749 Agricultural Water Management, 30, 155-173. 


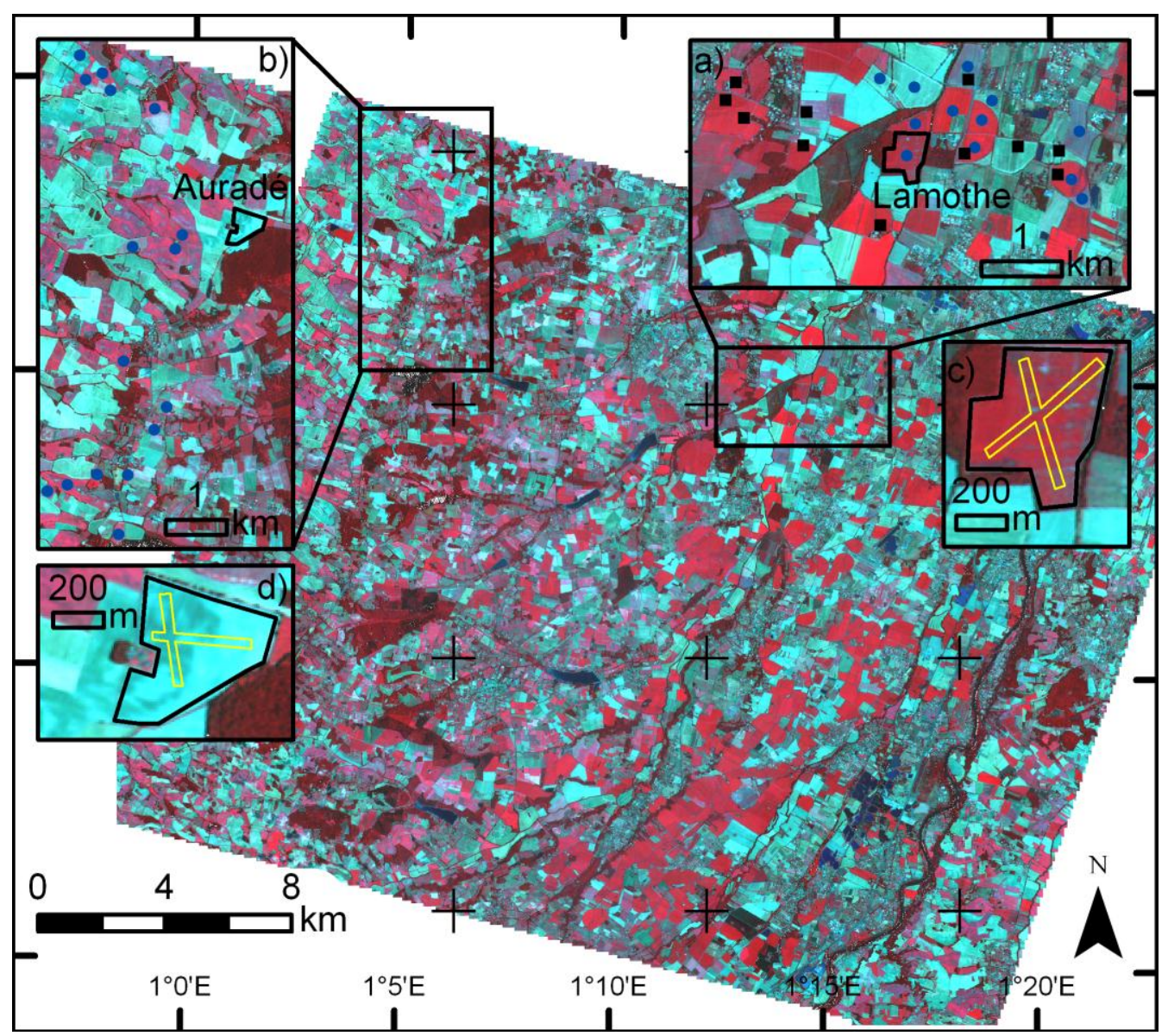

753 Figure 1: The study area as observed in a Formosat-2 image in July 2008. The areas where field data were collected are shown

754 in a) and b) frames; the black symbols indicate the locations of the elementary sampling units (11 ESUs near Lamothe), and

755 the blue disks indicate the fields for which the farmers provided grain yield data (12 fields near Lamothe, 16 fields near

756 Auradé). The so-called Lamothe (frame c) and Auradé (frame d) fields (delimited with black lines) are experimental fields that

757 belong to the CarboEurope-IP experiment; biomass measurements were performed along transects (in yellow). Black crosses

758 indicate the SAFRAN meteorological grid. 


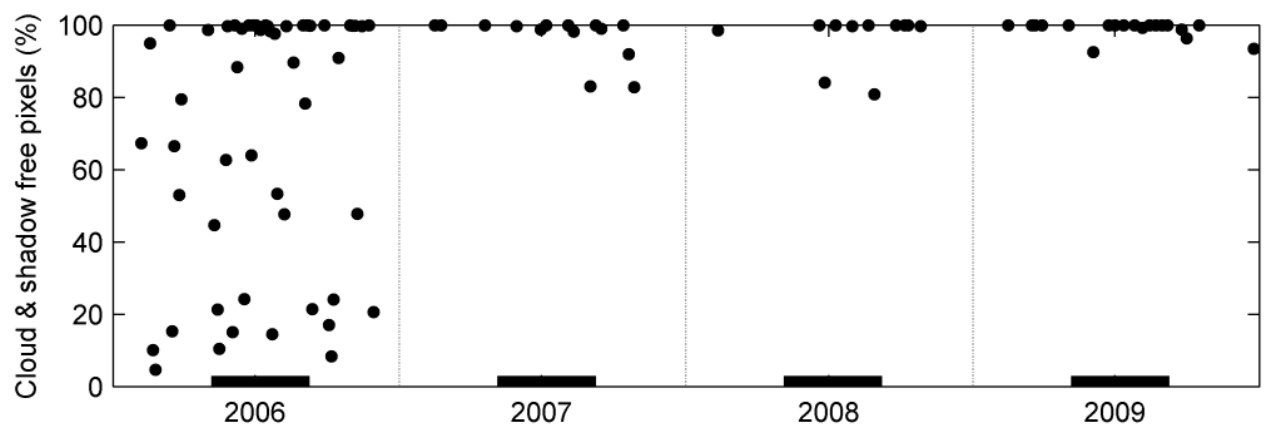

760

761 Figure 2: Dates of acquisition of the Formosat-2 images with the corresponding percentage of cloud-free and shadow-free

762 pixels. Thick black lines represent the standard summer crop-growing period (day of year 125 to 250 ).

763 


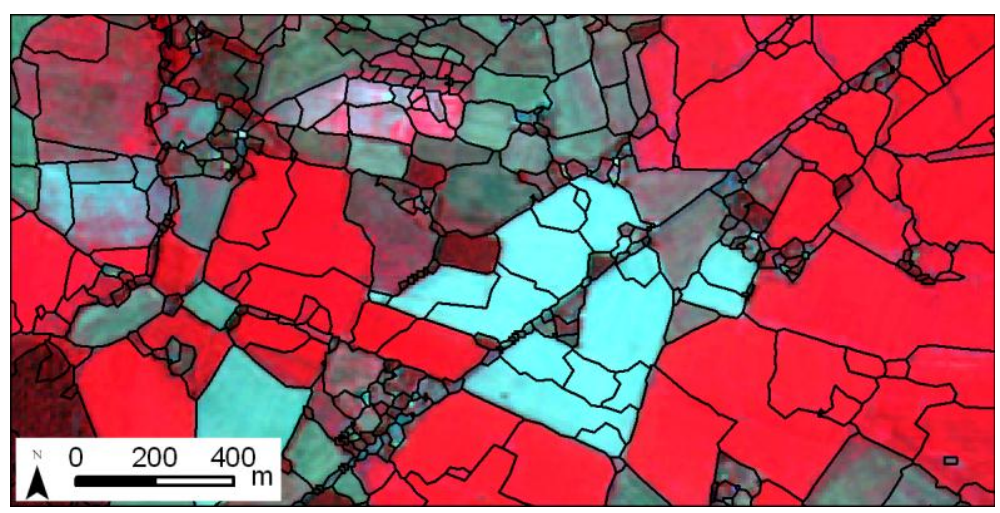

766

Figure 3: Map of delimitation of Homogenous Unit (black lines). The background corresponds to a Formosat-2 image in July 2008, displayed using a false colour composite.

768 


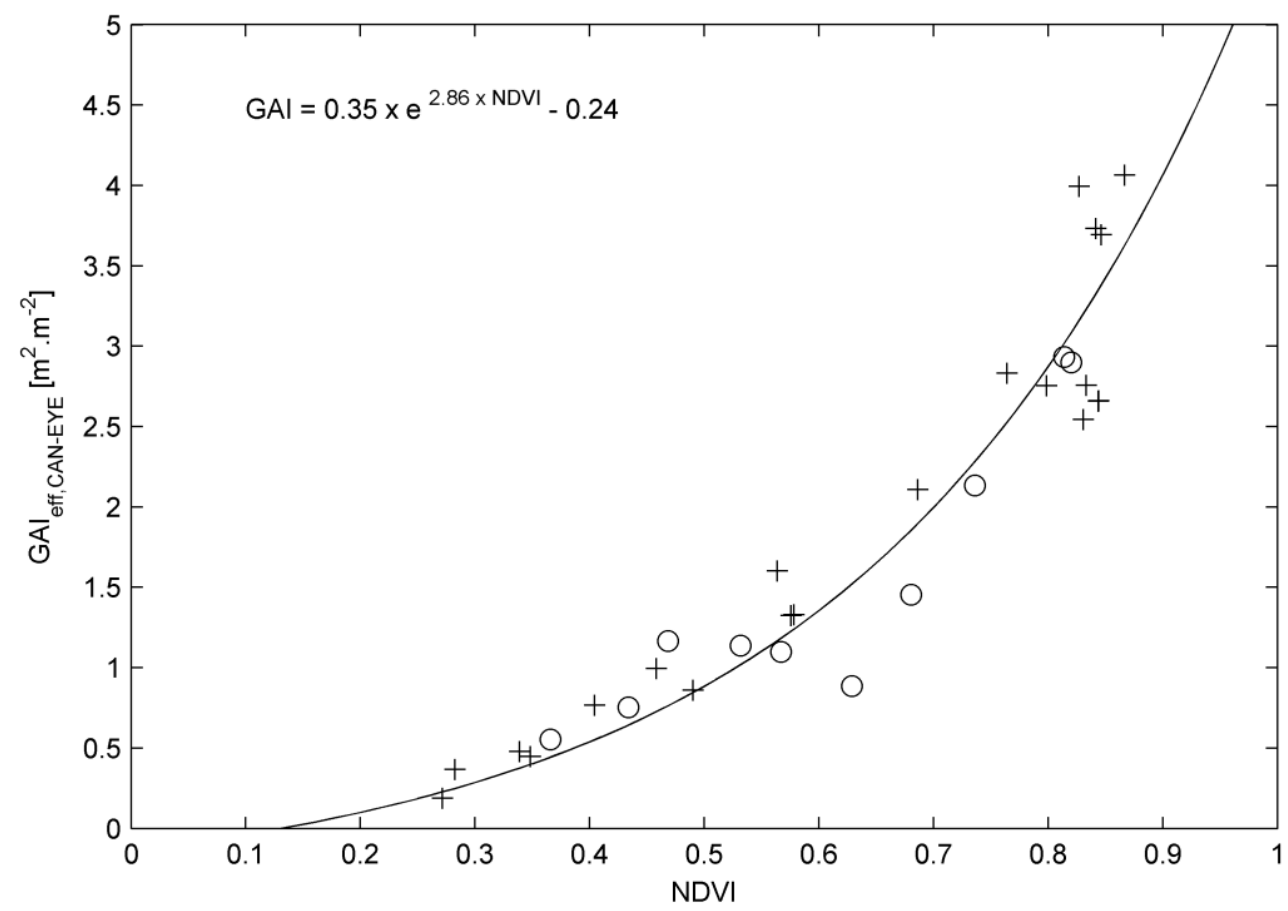

770

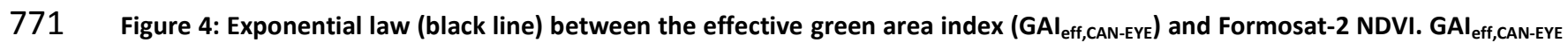

772 were collected per ESU and NDVI were averaged on a $3 \times 3$ pixels windows centred on the ESU. Pluses and circles indicate 773 maize and sunflower crops, respectively. 


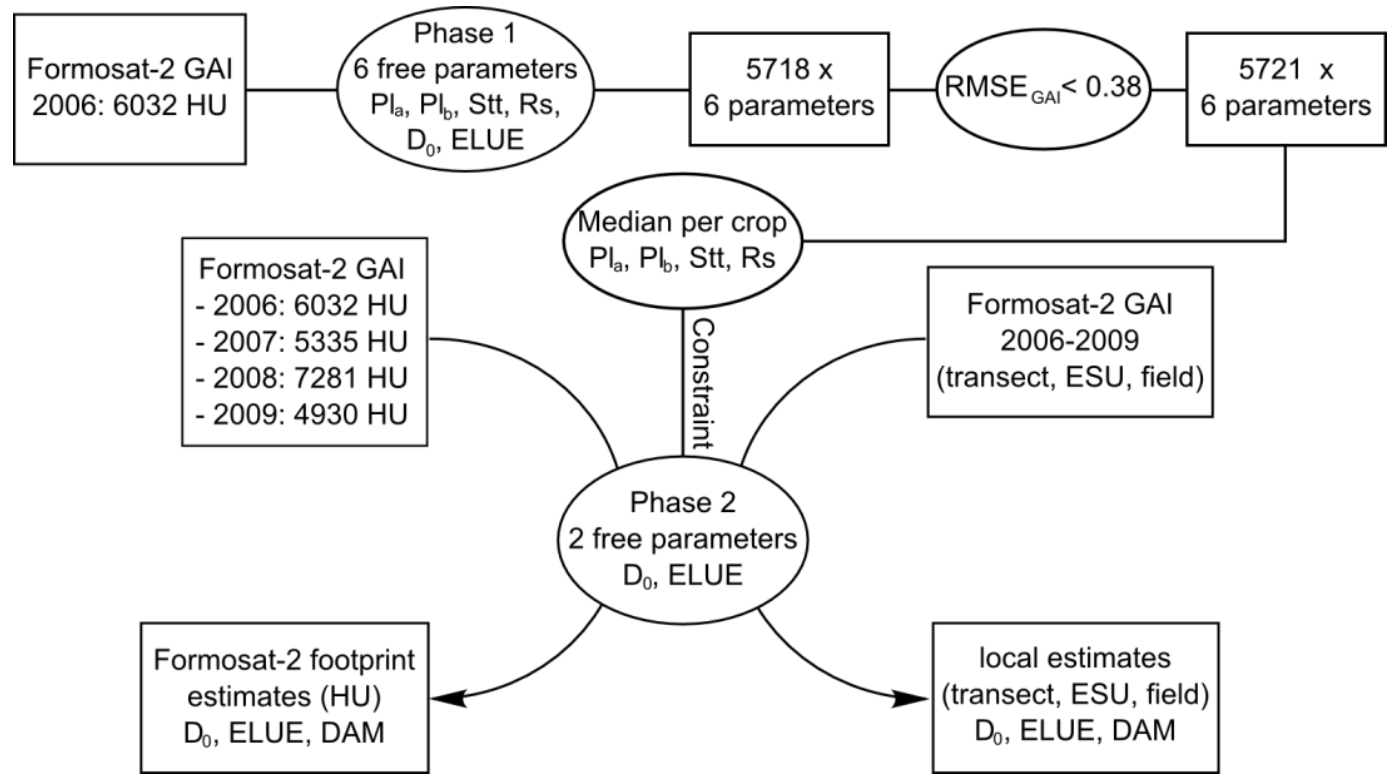

Figure 5: Description of the two phases of the calibration. Phase 1 and 2 describes the calibration of the crop-specific

parameters and the field-specific parameters, respectively. 


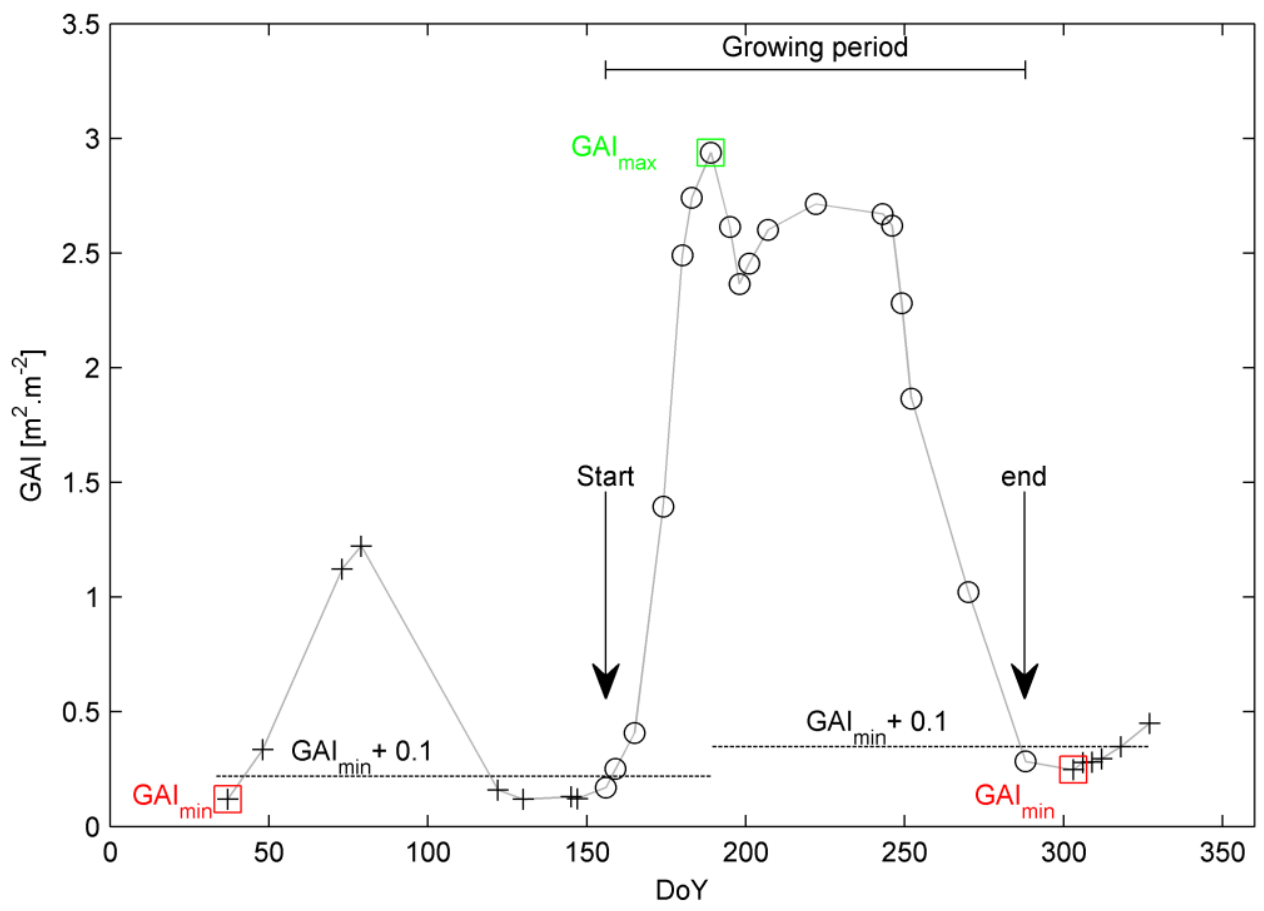

778

779 Figure 6: Example of the delimitation of the growing season on a Formosat-2 GAI time series for maize. The dashed line 780 indicates the normal law fitted on the GAI time series. The maximum GAI is framed in green and the two minimum GAI (from

781 each side) are framed in red. The horizontal dashed lines indicate the bare soil thresholds used to detect the start and the end

782 of the growing period. Circles and crosses indicate, respectively, selected and non-selected data acquired within the growing 783 period. 


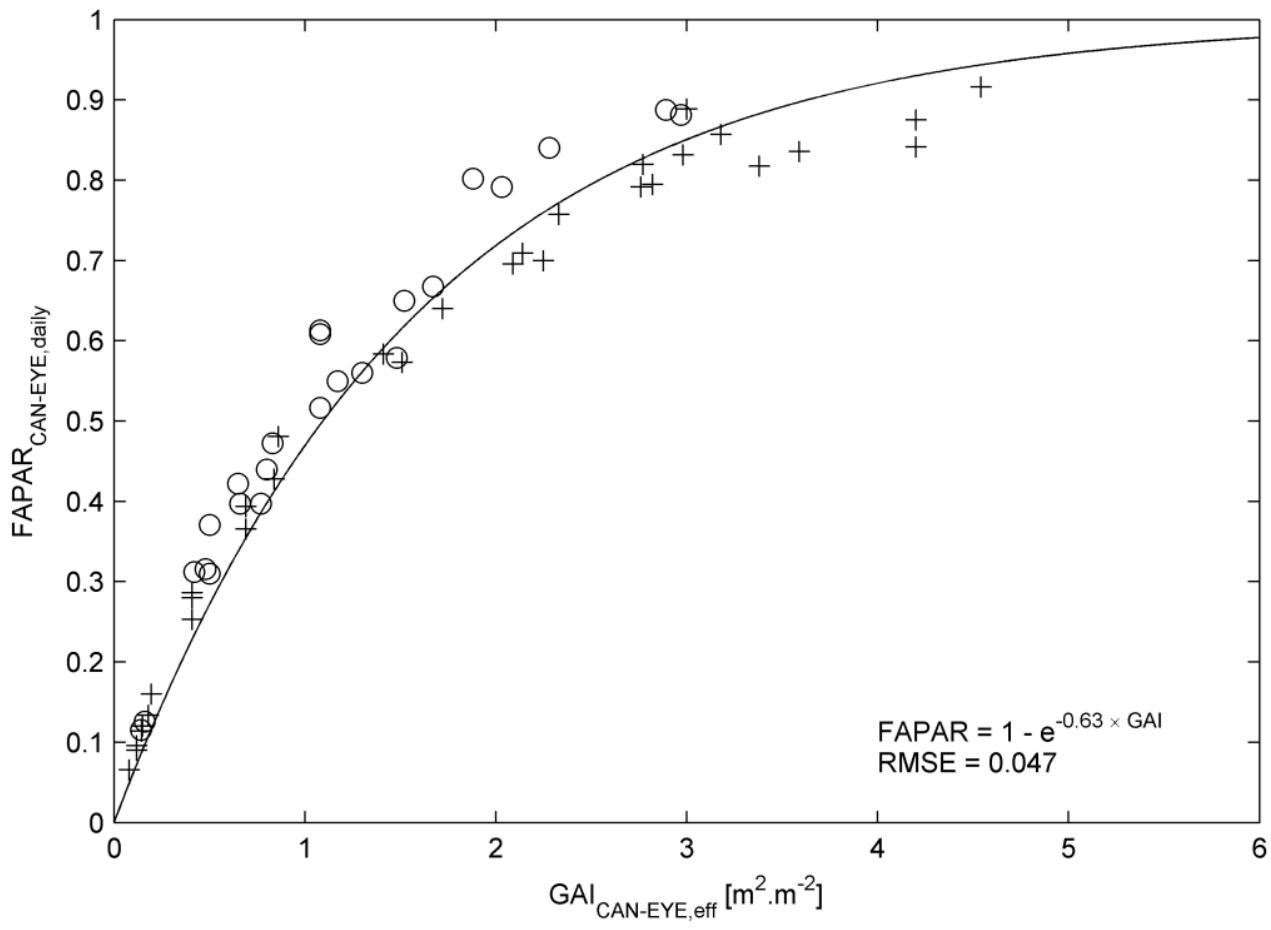

786 Figure 7: Relationship between the daily fraction of absorbed photosynthetically active radiation (FAPAR daily,CAN-EYE) and

787 effective green area index ( $\left.\mathrm{GAI}_{\mathrm{eff}, \mathrm{CAN}-\mathrm{EYE}}\right)$ derived from the hemispherical photographs. Pluses and circles indicate maize and 788 sunflower crops, respectively.

789 


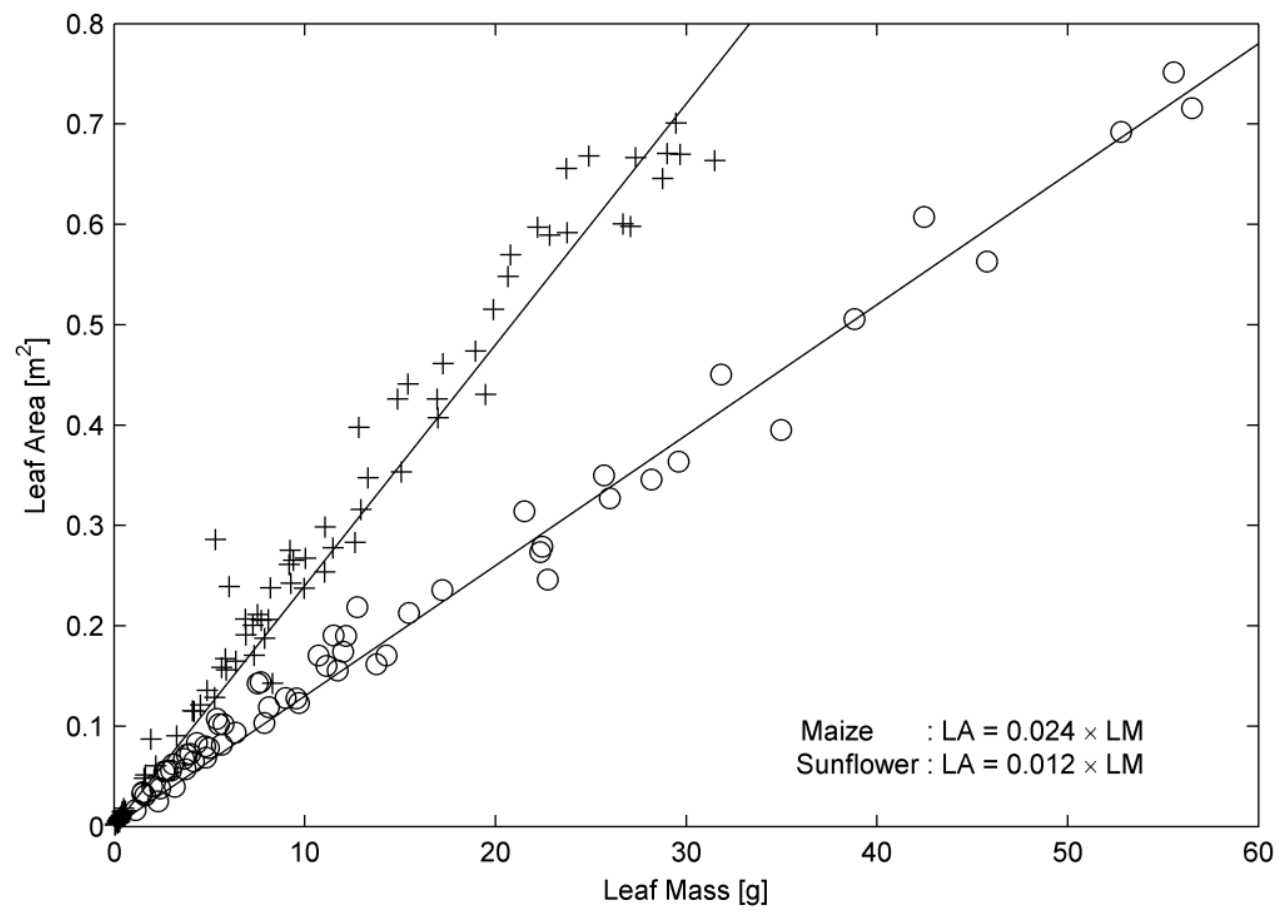

790

791 Figure 8: Relationship between leaf area (LA) and leaf mass (LM) estimated from destructive measurements. Pluses and circles indicate maize and sunflower crops, respectively. The slopes of the solid lines correspond to the SLA $\left(\mathrm{m}^{2} \cdot \mathrm{g}^{-1}\right)$ values. 

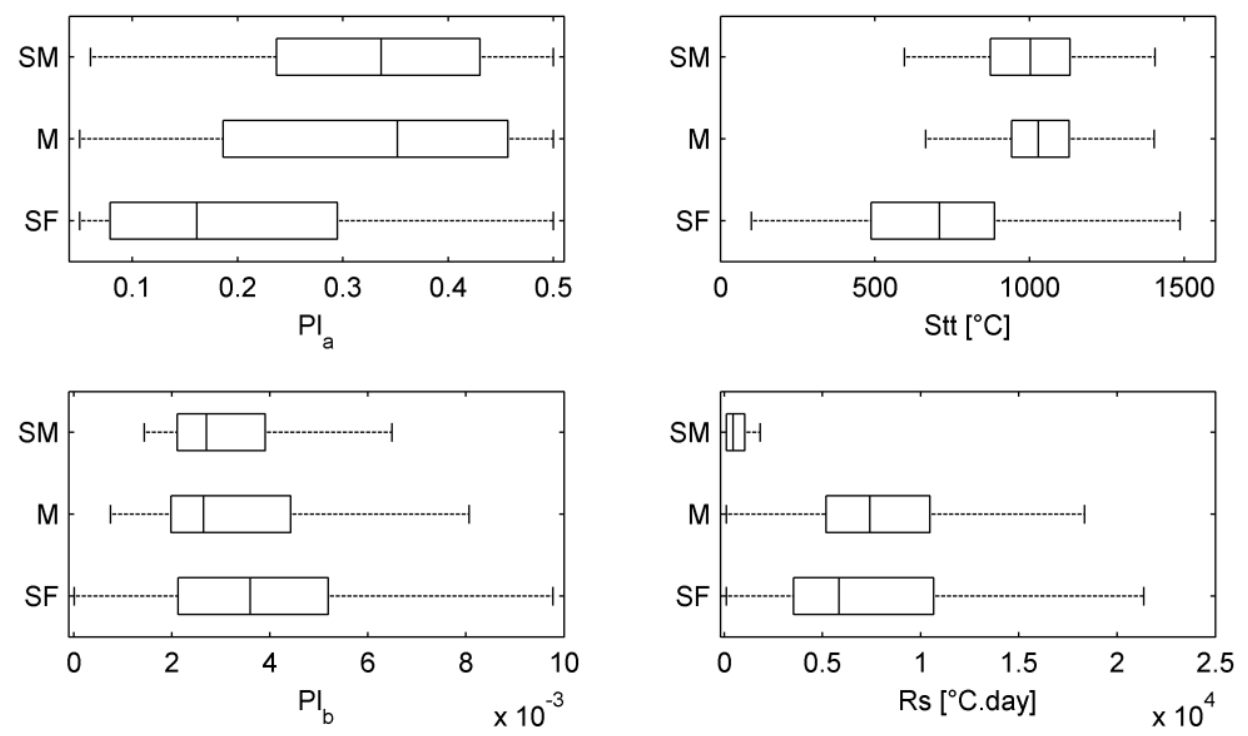

795 Figure 9: Distributions of crop-specific parameters of maize (grain: M and Silage: SM) and sunflower (SF) based on phase 1 of

796 the calibration applied on the $\mathbf{5 7 2 1} \mathrm{HU}$ of the 2006 Formosat-2 data set (1980 for grain maize, 97 for silage maize and 3644

797 for sunflower). Lower and upper quartiles and median values are presented. The whiskers (lines extending from each end of

798 the boxes) show the extent of the rest of the data, excluding outliers (not shown). 


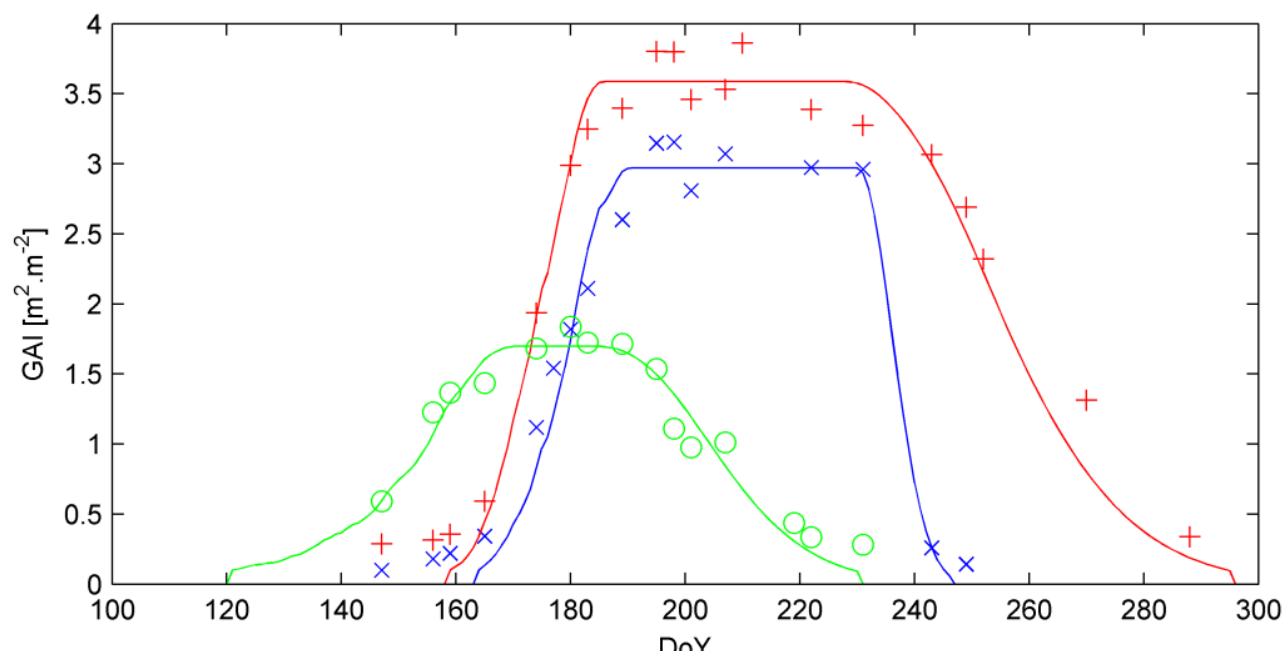

801 Figure 10: Example of three 2006 Formosat-2 GAl time series. Red pluses, blue crosses and green circles indicate grain maize,

802 silage maize and sunflower, respectively. Full lines show the SAFY simulations.

803

51 

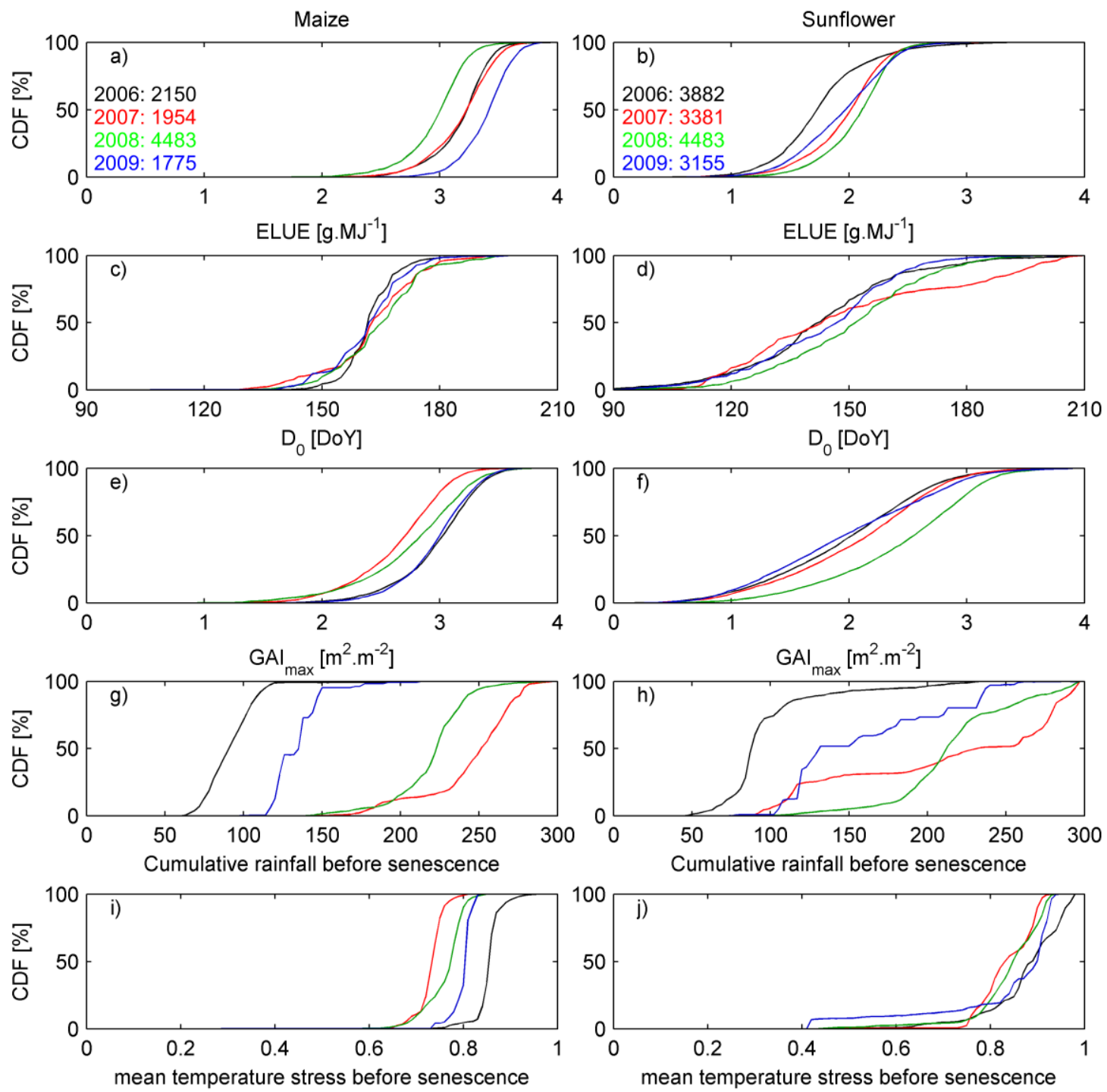

805 Figure 11: Cumulative distribution function (CDF) of ELUE ( $a$ and $b$ ), $D_{0}$ (c and $d$ ) and maximum GAI (GAI max, e and f) simulated

806 for maize (left column) and sunflower (right column) in 2006 (black), 2007 (red), 2008 (green) and 2009 (blue) over the whole

807 Formosat-2 footprint. The rainfall ( $\mathrm{g}$ and $\mathrm{h}$ ) was cumulated from $\mathbf{3 0}$ days before emergence to the start of the senescence.

808 The mean temperature stress ( $i$ and $j$ ) was cumulated from emergence to the start of the senescence. The amount of data 809 used is shown in a and b. 


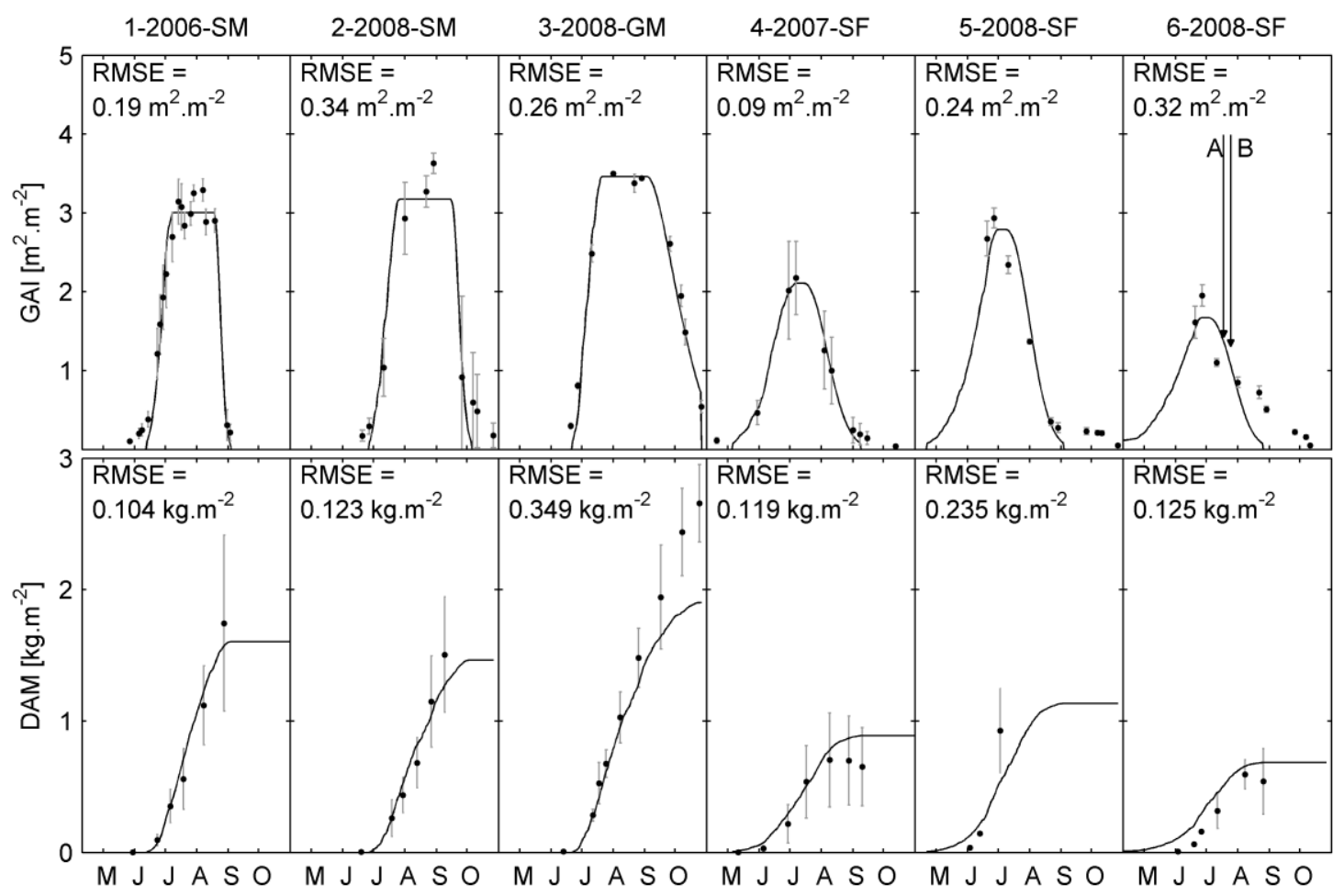

Figure 12: Green area index (GAI) and dry aboveground mass (DAM) simulated (lines) and measured (disks) over 6

814 experimental fields for the period 2006-2008. M: maize, SM: silage maize and SF: sunflower. Grey error bars on GAI and DAM correspond to the standard deviation computed from the pixels (GAI) and the measurements (DAM) performed either over photographs shown in Fig. 13. 
A) 17-Jul

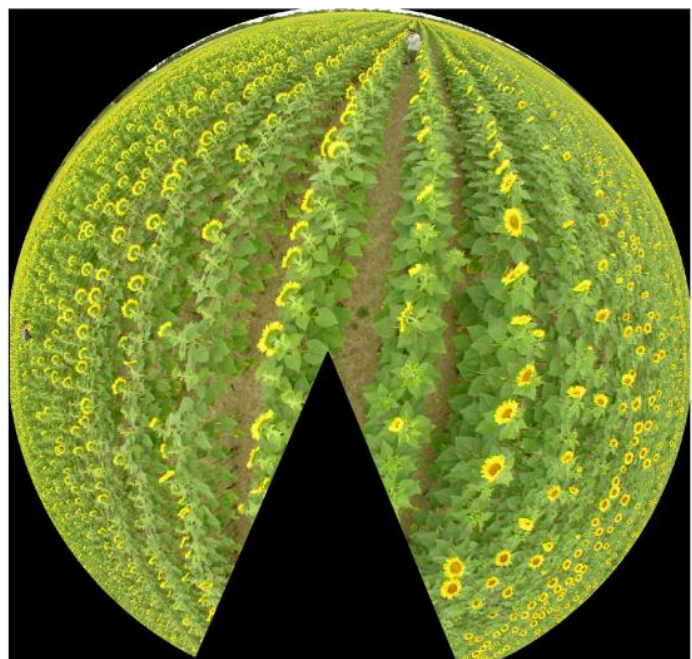

B) 24-Jul

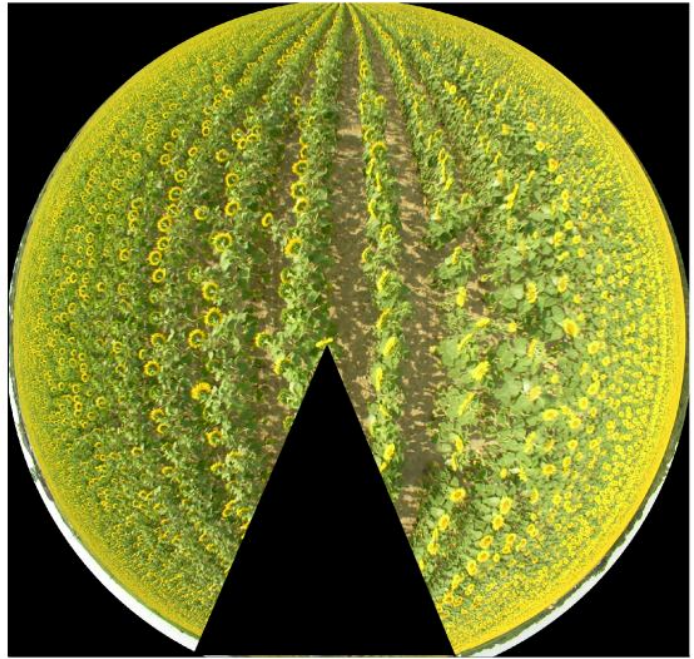

820 Figure 13: Hemispherical photographs taken in 2008 on July 17 (A) and July 24 (B) over the ESUs corresponding to case 6 of 821 Fig. 12. 


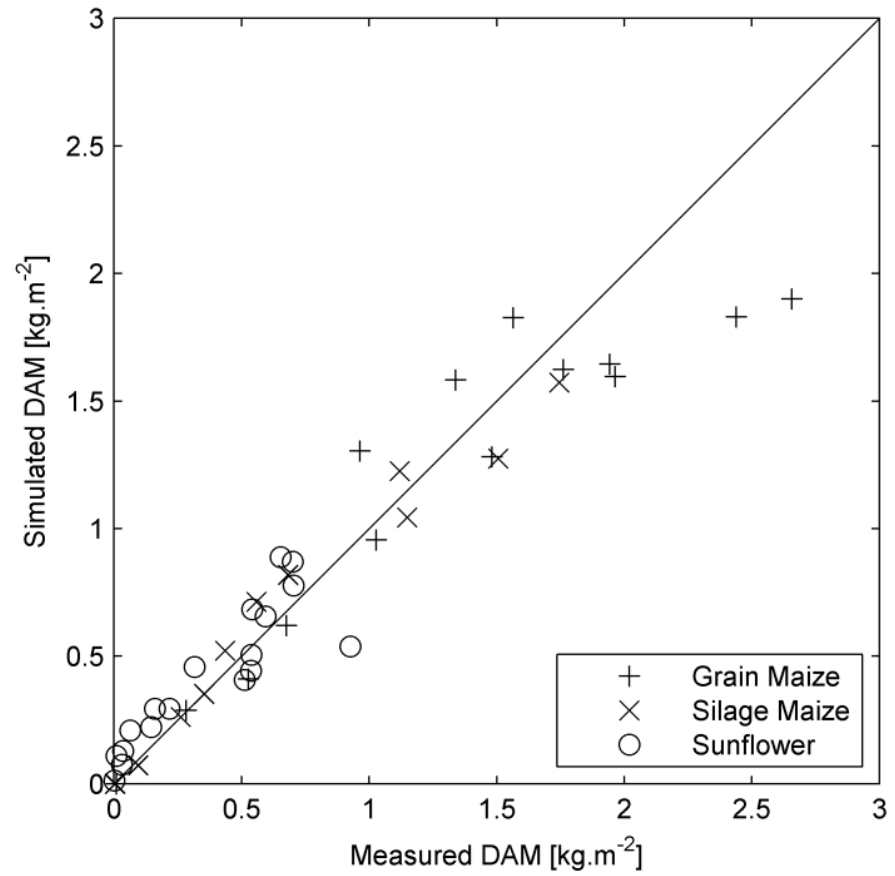

823

824 Figure 14: Comparison between the simulated and measured dry aboveground mass (DAM) over all of the experimental fields 825 for the period 2006-2009.

826 


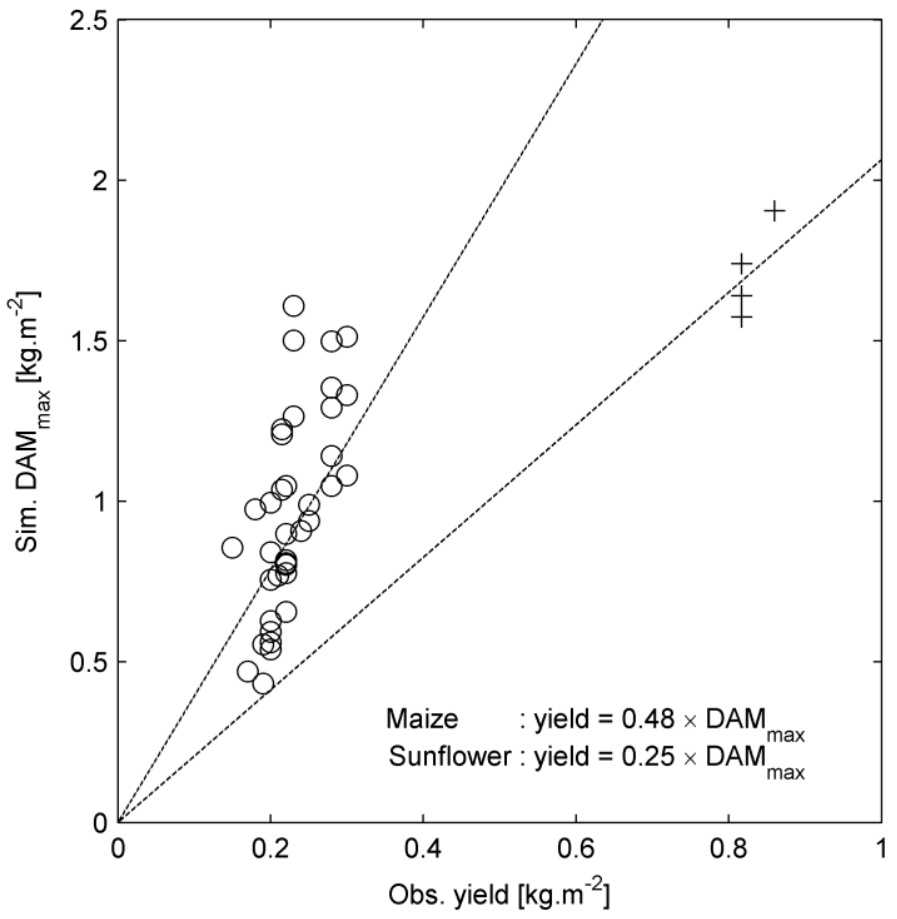

828 Figure 15: Relationship between simulated maximum dry aboveground mass (DAM max $_{\text {) }}$ and grain yields in 2006, 2007 and 8292008 , provided by farmers for 28 maize (+) and sunflower (o) crops. The slopes of the dashed lines correspond to the mean 830 harvest index.

831 

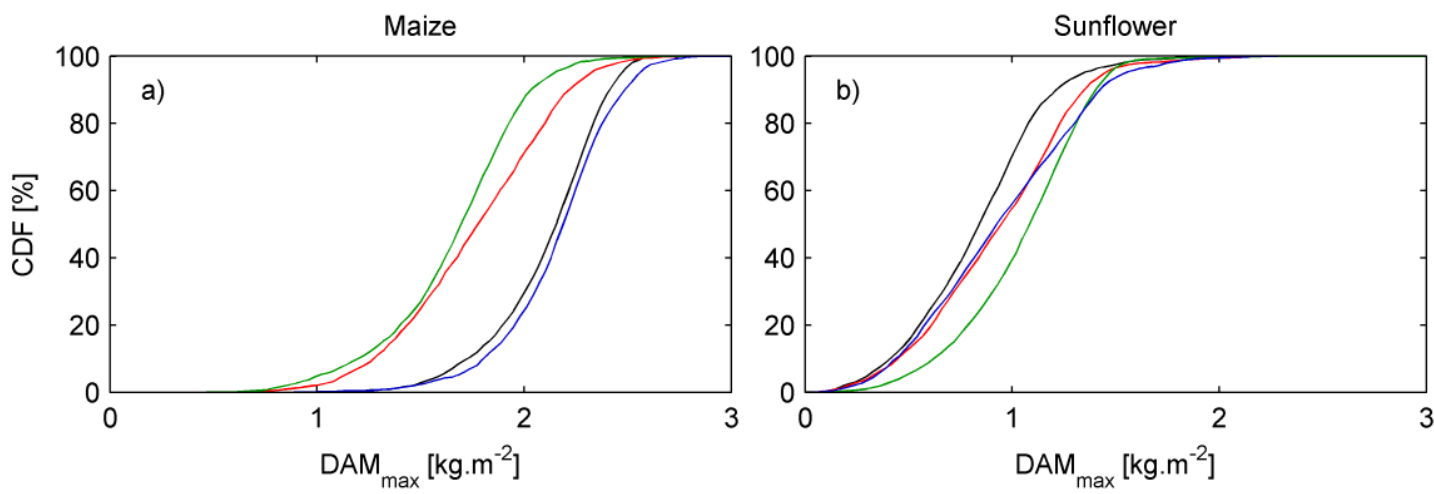

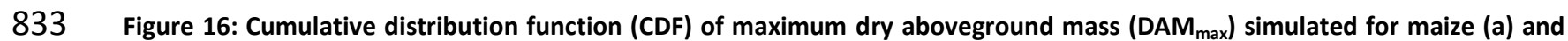
834 sunflower (b) in 2006 (black), 2007 (red), 2008 (green) and 2009 (blue) over the entire Formosat-2 footprint. The amount of data used is shown in Fig. 11 a and $b$.

836
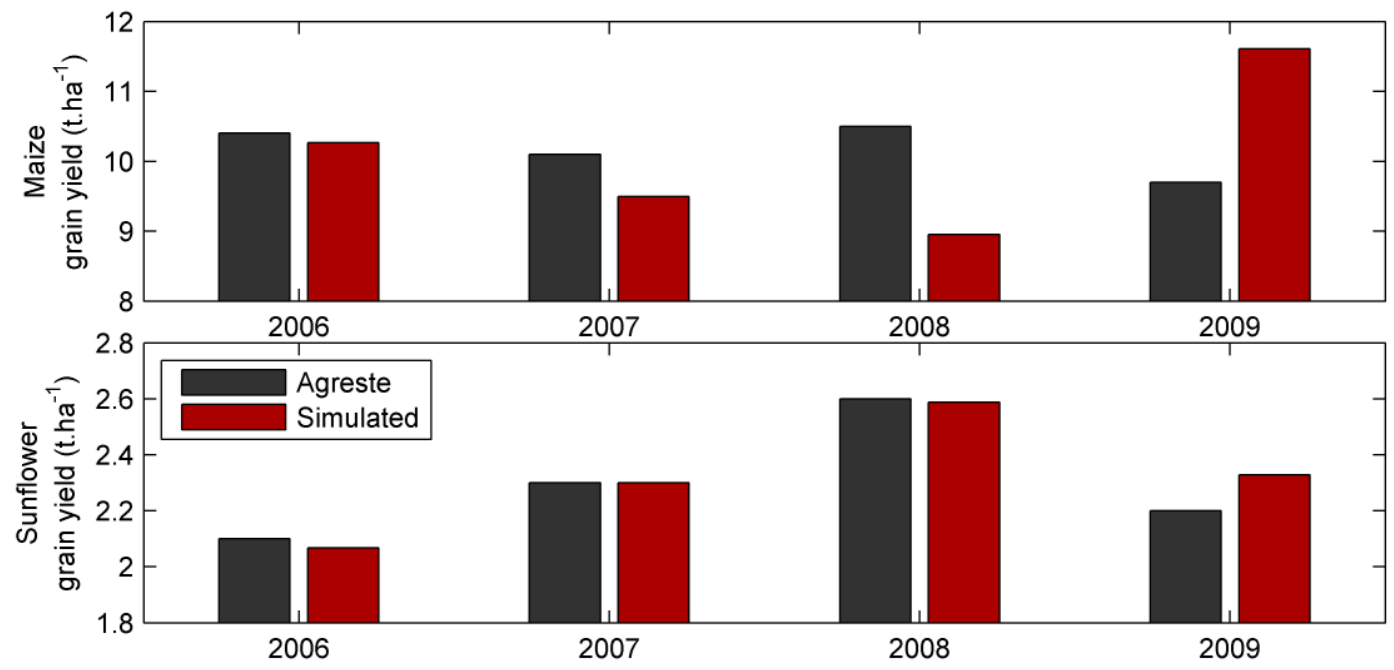

838 Figure 17: Comparison of the four-year grain yield (in t.ha ${ }^{-1}$ ) obtained from Agreste (2011) for the French department of Haute-Garonne and the yield simulated for the study area. 
843 Table 1: In situ measurements data description, including crop type, year of in situ measurements, and number of data 844 collected for GAI, FAPAR and DAM. The sampling scheme is given in the two last columns: ESU (with the number of sampled 845 field under bracket) or transect (Lamothe and Auradé). GAI and FAPAR were estimated from hemispherical photographs and 846 DAM was estimated from destructive measurements.

\begin{tabular}{cccc}
\hline Crop type & Year & GAI / FAPAR & DAM \\
\hline \multirow{4}{*}{ Maize } & 2006 & & Lamothe: 6 \\
\cline { 2 - 4 } & 2008 & \multirow{2}{*}{ ESU (3): 23} & ESU (1): 9 \\
\cline { 2 - 4 } & & & Lamothe: 6 \\
\hline \multirow{3}{*}{ Sunflower } & 2009 & & ESU (5): 5 \\
\cline { 2 - 4 } & 2007 & & Euradé: 7 \\
\cline { 2 - 4 } & 2009 & & ESU (2): 9 \\
\hline
\end{tabular}


Table 2: List of the SAFY input parameters and initial values estimated from the literature for $\varepsilon_{c}, T_{\min }, T_{o p t}, T_{\max }, \beta$ and DAM,

850 from measurements of $K_{\text {ext }}$ and SLA from the calibration procedure for the crop specific $\left(P_{a}, P_{b}, R s, S t t\right)$ and field specific $\left(D_{0}\right.$,

851 ELUE) parameters.

\begin{tabular}{|c|c|c|c|c|c|c|}
\hline Parameter type and name & Notation & Unit & Range & Grain Maize & Silage Maize & Sunflower \\
\hline \multicolumn{7}{|l|}{ Constant (literature) } \\
\hline Climatic efficiency & $\varepsilon_{\mathrm{C}}$ & - & & $0.48^{*}$ & $0.48^{*}$ & $0.48^{*}$ \\
\hline Initial dry aboveground mass & $\mathrm{DAM}_{0}$ & g.m $\mathrm{m}^{-2}$ & & 4.2 & 4.2 & 6.9 \\
\hline $\begin{array}{c}\text { Temperature for growth } \\
\text { [Minimal, Optimal, Maximal] }\end{array}$ & $\mathrm{T}_{\min }, \mathrm{T}_{\mathrm{opt}}, \mathrm{T}_{\max }$ & ${ }^{\circ} \mathrm{C}$ & & {$\left[\begin{array}{lll}8 & 30 & 45\end{array}\right]^{+}$} & {$\left[\begin{array}{lll}8 & 30 & 45\end{array}\right]^{+}$} & {$\left[\begin{array}{llll}8 & 28.5 & 42\end{array}\right]^{\ddagger}$} \\
\hline Polynomial degree & $\beta$ & - & & 2 & 2 & 3 \\
\hline \multicolumn{7}{|l|}{ Constant (measured) } \\
\hline Light-interception coefficient & $\mathrm{K}_{\mathrm{ext}}$ & - & & 0.63 & 0.63 & 0.63 \\
\hline Specific leaf area & SLA & $m^{2} \cdot g^{-1}$ & & 0.024 & 0.024 & 0.012 \\
\hline \multicolumn{7}{|l|}{ Calibrated (Crop-specific) } \\
\hline Partition-to-leaf function: par a & $\mathrm{Pl}_{\mathrm{a}}$ & - & {$\left[\begin{array}{llll}0.05 & 0.5]\end{array}\right.$} & 0.35 & 0.34 & 0.13 \\
\hline Partition-to-leaf function: par b & $\mathrm{Pl}_{\mathrm{b}}$ & - & {$\left[\begin{array}{ll}10^{-5} & \left.10^{-2}\right] \\
\end{array}\right.$} & 0.0026 & 0.0027 & 0.0033 \\
\hline Rate of senescence & Rs & ${ }^{\circ} \mathrm{C}$. day & {$\left[\begin{array}{ll}0 & \left.10^{5}\right]\end{array}\right.$} & 7410 & 457 & 5787 \\
\hline Temperature sum for senescence & Stt & ${ }^{\circ} \mathrm{C}$ & {$[0$ 2000] } & 1028 & 1002 & 713 \\
\hline \multicolumn{7}{|l|}{ Calibrated (Field-specific) } \\
\hline Day of plant emergence & $D_{0}$ & DoY & {$\left[\begin{array}{lll}90 & 250\end{array}\right]$} & & & \\
\hline Effective light-use efficiency & ELUE & g. $\mathrm{MJ}^{-1}$ & {$[0.56]$} & & & \\
\hline
\end{tabular}

* Varlet-Grancher et al. (1982)

+ Drouet and Pages (2003)

$852 \quad{ }^{\ddagger}$ Stics website (http://www.avignon.inra.fr/agroclim_stics/) 
Table 3: Statistics derived from the comparison of the SAFY simulated and the measured dry aboveground mass (DAM).

856

\begin{tabular}{lccc}
\hline & Maize & Sunflower & All crops \\
\hline $\mathrm{N}$ & 26 & 18 & 44 \\
\hline $\mathrm{RMSE}\left(\mathrm{kg} \cdot \mathrm{m}^{-\imath}\right.$ & 0.252 & 0.145 & 0.215 \\
\hline RRMSE $(\%)$ & 24.67 & 39.11 & 28.44 \\
\hline Bias $\left(\mathrm{kg} \cdot \mathrm{m}^{-2}\right)$ & -0.070 & 0.049 & -0.021 \\
\hline $\mathrm{r}^{2}$ & 0.91 & 0.78 & 0.92 \\
\hline
\end{tabular}

857 
858

61 


\section{Appendix 1: Overview of the SAFY model.}

860 The simple algorithm for yield estimates (SAFY, Duchemin et al. 2008a) is a daily time-step

861 model that simulates time series of leaf area index (LAI) and dry aerial mass (DAM) from the air

862 temperature ( $\mathrm{Ta})$ and the global incoming radiation $(\mathrm{Rg})$. The simulations begin on the plant

863 emergence day $\left(D_{0}\right)$. $D_{0}$ depends on agricultural practices (in particular sowing date and depth)

864 and on the pedoclimatic conditions and constrains the phase of the LAl time course.

865 Daily DAM production $\left(\Delta_{\text {DAM }}\right)$ is calculated through the approach of Monteith $(1977$, Eq. 2$)$ using 866 an effective light-use efficiency (ELUE), a daily temperature stress factor $\left(F_{T}\right)$ and the daily 867 photosynthetically active radiation absorbed by plants (APAR). The ELUE expresses the 868 conversion of the APAR into DAM. It is supposed to account for all agri-environmental stresses, 869 such as water and nitrogen supplies, except for temperature. It constrains the amplitude of the

870 GAl time course. The temperature stress function is a classical Polynomial (Eq. 3) of $\beta$ Degree 871 defined by an optimal daily mean air temperature $\left(T_{\text {opt }}\right)$ for maximum crop functioning and two 872 extreme temperatures ( $T_{\min }$ and $T_{\max }$ ) beyond which the plant growth stops (after Brisson et al. 873 2003). The APAR (Eq. 4) is computed using the daily incoming global radiation (Rg), the climatic

874 efficiency $\left(\varepsilon_{c}\right)$ and the fraction of the photosynthetically active portion of solar radiation 875 absorbed by green plants (FAPAR). In the SAFY model, the FAPAR is estimated using Beer's law

876 (Eq. 5), where $k_{\text {ext }}$ defines the light-extinction coefficient (Monsi and Saeki 1953).

877

$\Delta_{D A M}=E L U E \times F_{T}(T a) \times A P A R$ 
$878\left\{\begin{array}{ccc}F_{T}(T a)=1-\left(\frac{T_{o p t}-T a}{T_{o p t}-T_{\min }}\right)^{\beta} \quad \text { if } & T_{\min }<T a<T_{o p t} \\ F_{T}(T a)=1-\left(\frac{T_{o p t}-T a}{T_{o p t}-T_{\max }}\right)^{\beta} & \text { if } & T_{\max }>T a>T_{o p t} \\ F_{T}(T a)=0 & \text { if } & T a<T_{\min } \text { OR } T a>T_{\max }\end{array}\right.$

$879 \quad A P A R=F A P A R \times \varepsilon_{C} \times R g$

$880 \quad F A P A R=1-e^{-k_{e x t} \times L A I}$

881 During plant growth, a fraction of the daily plant DAM production is partitioned to the dry leaf

882 biomass. This fraction is calculated using the partition-to-leaf function PI (Eq. 6, after Maas

883 1993), which varies from 0 to 1 . PI is a function of the daily air temperature cumulated from

884 plant emergence (SMT: sum of temperature, Eq. 7) and two parameters: $\mathrm{Pl}_{\mathrm{a}}$ and $\mathrm{Pl}_{\mathrm{b}}$. It should be 885 noted that $\left(1-\mathrm{Pl}_{\mathrm{a}}\right)$ defines the rate of biomass allocation to leaves at plant emergence. Daily 886 leaf mass production $\left(\Delta_{\mathrm{DAM}} \times \mathrm{PI}\right)$ is converted into daily leaf area growth $\left(\Delta_{\text {LAI }}^{+}\right)$based on the 887 specific leaf area (SLA, Eq. 8). Leaf senescence $\left(\Delta_{\text {LAI }}^{-}\right)$begins when the SMT reaches a given 888 threshold (Stt, sum of temperature for senescence). It is modelled by a function (Eq. 9) based on 889 the rate of senescence coefficient (Rs). The LAI is updated from the balance of $\Delta_{\text {LAI }}^{+}$and $\Delta_{\text {LAI }}^{-}$(Eq. 890 10).

892

$$
S M T=\sum_{D_{0}}^{t}\left(T a_{t}-T_{\min }\right) \cdot d t
$$


893 If $\mathrm{Pl}>0, \Delta_{L A l}^{+}=\Delta_{D A M} \times P l \times S L A$

894 If SMT>Stt, $\Delta_{L A I}^{-}=L A I \times \frac{S M T-S t t}{R s}$

$895 L A I_{t}=L A I_{t-1}+\Delta_{L A I}^{+}-\Delta_{L A I}^{-}$ 